\title{
Non-Newtonian Flow Characteristics of Heavy Oil in the Bohai Bay Oilfield: Experimental and Simulation Studies
}

\author{
Xiankang Xin ${ }^{1}{ }^{(1)}$, Yiqiang $\mathrm{Li}^{1}$, Gaoming Yu ${ }^{2, *}$, Weiying Wang ${ }^{2}$, Zhongzhi Zhang ${ }^{3}$, \\ Maolin Zhang ${ }^{2}$, Wenli Ke ${ }^{2}$, Debin Kong ${ }^{1}$ (D), Keliu Wu ${ }^{4}$ and Zhangxin Chen ${ }^{4}$ \\ 1 College of Petroleum Engineering, China University of Petroleum, Beijing 102249, China; \\ xiankang.xin@hotmail.com (X.X.); lyq13504598848@163.com (Y.L.); mrdebin@163.com (D.K.) \\ 2 College of Petroleum Engineering, Yangtze University, Wuhan 430100, China; WWY59@163.com (W.W.); \\ zmlmhy65@126.com (M.Z.); kewenli2006@163.com (W.K.) \\ 3 College of Chemical Engineering, China University of Petroleum, Beijing 102249, China; bjzzzhang@163.com \\ 4 Department of Chemical and Petroleum Engineering, University of Calgary, Calgary, AB T2N 1N4, Canada; \\ wukeliu19850109@163.com (K.W.); zhachen@ucalgary.ca (Z.C.) \\ * Correspondence: ygm@yangtzeu.edu.cn; Tel.: +86-27-6911-1069
}

Received: 11 September 2017; Accepted: 23 October 2017; Published: 25 October 2017

\begin{abstract}
In this paper, physical experiments and numerical simulations were applied to systematically investigate the non-Newtonian flow characteristics of heavy oil in porous media. Rheological experiments were carried out to determine the rheology of heavy oil. Threshold pressure gradient (TPG) measurement experiments performed by a new micro-flow method and flow experiments were conducted to study the effect of viscosity, permeability and mobility on the flow characteristics of heavy oil. An in-house developed novel simulator considering the non-Newtonian flow was designed based on the experimental investigations. The results from the physical experiments indicated that heavy oil was a Bingham fluid with non-Newtonian flow characteristics, and its viscosity-temperature relationship conformed to the Arrhenius equation. Its viscosity decreased with an increase in temperature and a decrease in asphaltene content. The TPG measurement experiments was impacted by the flow rate, and its critical flow rate was $0.003 \mathrm{~mL} / \mathrm{min}$. The TPG decreased as the viscosity decreased or the permeability increased and had a power-law relationship with mobility. In addition, the critical viscosity had a range of $42-54 \mathrm{mPa} \cdot \mathrm{s}$, above which the TPG existed for a given permeability. The validation of the designed simulator was positive and acceptable when compared to the simulation results run in ECLIPSE V2013.1 and Computer Modelling Group (CMG) V2012 software as well as when compared to the results obtained during physical experiments. The difference between 0.0005 and $0.0750 \mathrm{MPa} / \mathrm{m}$ in the TPG showed a decrease of $11.55 \%$ in the oil recovery based on the simulation results, which demonstrated the largely adverse impact the TPG had on heavy oil production.
\end{abstract}

Keywords: flow characteristics; heavy oil; rheology; threshold pressure gradient; numerical simulation

\section{Introduction}

World crude oil demands have grown at an average rate of 1.30\% per year during 2006-2016 [1]. According to the International Energy Agency (IEA) statistics, the reserves of heavy oil that are of the same order of magnitude as the ones of conventional oils are abundant worldwide. Heavy oil has been proved to be a significant hydrocarbon resource for meeting the global energy consumption historically, and this is likely to continue [2]. In the petroleum industry, liquid petroleum with a high viscosity, an American Petroleum Institute (API) gravity less than $20^{\circ}$ and a difficult flow under normal reservoir 
conditions is referred to as heavy crude oil or heavy oil [3,4]. The physical properties of heavy oil composed of heavy molecular compositions are different from those of conventional oil as they have different rheological properties and flow characteristics.

The rheology of heavy oil crucially affects upstream recovery and transportation [5-7]. Several experimental studies have focused on the rheology of heavy oil. Generally, these studies concentrate on three aspects. (1) The rheology of heavy oil is highly dependent on temperature [8,9]. At a low temperature, liquid molecules do not have enough thermal energy to overcome the energy barrier to jump into unoccupied sites or holes $[10,11]$, which makes it difficult for the liquid to flow and results in high viscosity. However, a low increase in temperature can promote a great reduction in viscosity [12]. At a high temperature, viscosity reduces, elastic behaviors tend to vanish, and heavy oil demonstrates Newtonian behavior [5]. (2) The composition of heavy oil, particularly the content of heavier components, such as asphaltenes and resins, plays a dominant role in viscosity and rheology [13-15]. The viscosity of a heavy oil can increase above a critical concentration due to the structural changes brought about by the entanglement and overlapping of solvated asphaltene [16]. Resins can develop a steric layer around asphaltenes to prevent them from overlapping, but the impact is lower than that observed from asphaltenes on viscosity [17]. (3) The rheology of heavy oil exhibits a Bingham behavior, which has been demonstrated in several studies [18-21]. Most of these previous studies focused only on one or two aspects and thus, this work cannot be considered as being comprehensive.

The rheology of heavy oil is primarily responsible for its flow characteristics in porous media. Heavy oil starts to flow when the pressure gradient exceeds the TPG and the flow does not follow Darcy's law [22,23]. It is similar to the Bingham fluid because it does not express a shear rate until a specific stress (i.e., yield stress) is imposed. The constitutive equation for the Bingham fluid can be written $[11,24,25]$ :

$$
\left\{\begin{array}{l}
\boldsymbol{\tau}=\left[\mu_{B}+\frac{\tau_{y}}{\left|I I_{\dot{\gamma}}\right|^{1 / 2}}\right] \dot{\gamma} \quad I I_{\tau} \geq \tau_{y}{ }^{2} \\
\dot{\gamma}=\mathbf{0} \quad I I_{\tau}<\tau_{y}{ }^{2}
\end{array}\right.
$$

where $\tau$ is the stress tensor [11]; $\mu_{B}$ is the plastic viscosity in Pa.s; $\tau_{y}$ is the yield stress in Pa; $\dot{\gamma}$ is the rate of deformation tensor; $I I_{\dot{\gamma}}$ is the second invariant of $\dot{\gamma}$, and $I I_{\dot{\gamma}}=\frac{1}{2}\left[(\operatorname{tr} \dot{\gamma})^{2}-\operatorname{tr} \dot{\gamma}^{2}\right]$ where $\operatorname{tr} \dot{\gamma}$ is the trace of $\dot{\gamma}$ [25]; $I I_{\tau}$ is the second invariant of $\tau$. The TPG is one of the key parameters of the Bingham fluid found in heavy oil reservoirs [19]. It has a significant influence on oil productivity and recovery in addition to affecting the determination of reasonable well spacing and the distribution of remaining oil [26]. The accurate measurement of the TPG is critical, and many experimental methods have been proposed for addressing this need. The commonly used steady-state method includes a constant pressure method and a constant flow rate method [27]. An unsteady method based on a theoretical model of non-Newtonian flow of heavy oil is another method that can be used to measure the TPG [28]. A capillary balance method relies on the principle of a connector to obtain the TPG [29]. It was proved in our previous work that the TPG was affected by a displacing rate used in the TPG measurement experiment [30]. Nevertheless, few of these methods have considered the influence of a flow rate on the TPG. Furthermore, the TPG and its existence are influenced by many factors [31,32], but the critical condition for the existence of the TPG is rarely studied.

There are also many flow experiment methods [33,34]. The steady-state method is most commonly employed as the test method of flow characteristics over the other methods due to its great advantages of test system stability, high precision and reliable data [23,34-36]. The single-phase flow of heavy oil has been studied by the steady-state method $[9,19,23]$. Heavy oil does not flow until the displacing pressure gradient reaches the TPG. When the displacing pressure gradient is higher than the TPG, the flow rate of heavy oil increases linearly [19]. The flow behavior of heavy oil does not follow Darcy's law as it belongs to non-Newtonian flow [31,37,38]. The steady-state method applied in the multiphase flow of heavy oil was widely used to obtain the relative permeability 
for each phase, where the saturations, flow rates, and pressure gradients are measured and used in Darcy's law $[33,36,39]$. However, in this process, the existence of TPG and non-Newtonian flow were of little concern.

Unfortunately, most commercial numerical simulation software is based on the assumption of Darcy flow in porous media, and they do not take non-Newtonian flows into account. The simulation and forecast results are often erroneous when used to simulate the flow of fluids with non-Newtonian flow characteristics, because non-Newtonian flow influences the production of crude oil [40]. In order to simulate the displacement of heavy oil accurately, the relative permeability, one of the key parameters required in numerical simulation, was recalculated to address the effect of viscosity. Wang et al. [41] investigated that relative permeabilities were a function of oil viscosity under the same injection flow rate with the same water phase. Torabi et al. [42] predicted heavy oil/water relative permeability by modified Corey-based correlations. Mai [43] reported that Johnson-Bossler-Naumann (JBN) method allowed for the calculation of apparent relative permeability curves that could be incorporated into reservoir simulators, and the effect of oil viscosity could be addressed through its effect on the apparent relative permeabilities calculated. Doorwar et al. [44] considered that relative permeability functions needed to be modified to simulate unstable displacements with conventional simulators, and high viscosity ratio led to viscous fingering, which affected the observed relative permeability curves; they developed a lumped-finger model to modify multiphase flow equations and to yield pseudo relative permeability functions that accounted for viscous fingering. To a certain extent, it is a solution that can be incorporated into conventional simulators to improve the accuracy of heavy oil simulation. However, the presence of TPG in the flow of Bohai Bay heavy oil cannot been described by simply using the recalculated relative permeability in conventional simulators. Furthermore, various attempts to model the Bingham fluid have been made [45-48], with these studies providing some theoretical references for the non-Newtonian flow simulation of heavy oil with the TPG. The governing equations for non-Newtonian flow are nonlinear and are generally solved by numerical methods [49]. The most well-known method used to numerically solve the flow of multiphase fluids in porous media is the implicit pressure explicit saturation method (IMPES). In IMPES, the pressure equation is implicitly solved and the saturation equation is explicitly solved [50-52]. Although the numerical dispersion is inevitable in the process of solving, IMPES has still been widely applied in numerical simulations because it demands less computer memory and calculation work $[53,54]$ since it was introduced by Sheldon et al. [55] and Stone and Garder [56]. It is necessary to design a simulator that can accurately describe the non-Newtonian flow characteristics of heavy oil with the TPG, where IMPES is applied to obtain solutions with an acceptable numerical dispersion and a high running speed.

In this paper, an experimental study was conducted to investigate three aspects of the rheology of heavy oil, including the effect of temperature and asphaltene content on the rheology of heavy oil as well as the Bingham behavior of heavy oil. Considering the influence of a flow rate on the TPG in the TPG measurement experiment, a small flow rate of $0.002 \mathrm{~mL} / \mathrm{min}$ was used to measure the TPG, with this experimental method known as a micro-flow method. Moreover, the critical viscosity for the existence of the TPG at a given permeability was determined by physical experiments. Following this, flow experiments were carried out by the steady-state method to obtain the overall flow curve of the heavy oil to analyze the relationship between the displacement pressure gradient and the flow rate as well as the difference between the single-phase flow and the oil-water two-phase flow. Finally, considering the obvious Bingham behavior of heavy oil in Bohai Bay oilfield that can be seen in the third section of this paper, we directly corrected Darcy's law and proposed the flow model based on its flow experiments, which could better describe the non-Newtonian flow characteristics with the TPG compared with the simple use of recalculated relative permeability. An in-house developed novel three-dimensional (3D) two-phase heavy oil simulator was designed, where the IMPES was applied. The validation of this simulator was done by comparing with the simulation results run in ECLIPSE V2013.1 and CMG V2012 software as well as with the results obtained during physical experiments. A TPG sensitivity analysis was undertaken using the simulator to provide a 
more complete understanding of the influence of the TPG on the heavy oil production. These results and numerical simulations offer a tool to study the flow of heavy oil in porous media.

\section{Methodology}

\subsection{Physical Experiments}

The information of heavy oil samples used in this paper are given in Table 1. The heavy oil sample \#1 was the original crude oil from a well in Bohai Bay oilfield in China; the heavy oil samples \#5 and \#6 were reconstituted oil obtained by dispersing the asphaltenes extracted from the original oil \#1 into the de-asphalted original oil; and the heavy oil samples \#2, \#3 and \#4 were reconstituted oils made by mixing the original oil \#1 with kerosene. The basic parameters of core samples are presented in Table 2. The cores \#1-3, \#27-29 and \#32-34 were obtained from the same large artificial core. We considered that they had the same properties although their measured permeabilities and porosities were slightly different. The information of water used in the paper is also provided in Table 3.

Table 1. The information of heavy oil samples used in this paper.

\begin{tabular}{|c|c|c|c|c|c|c|c|}
\hline \multirow{2}{*}{ Parameters } & & \multicolumn{6}{|c|}{ Heavy Oil Samples } \\
\hline & & $\# 1$ & $\# 2$ & $\# 3$ & $\# 4$ & $\# 5$ & $\# 6$ \\
\hline \multirow{12}{*}{ Composition, mol.\% } & $\mathrm{C}_{3}$ & 0.12 & 0.09 & 0.03 & 0.01 & 0.00 & 0.00 \\
\hline & $\mathrm{i}-\mathrm{C}_{4}$ & 0.21 & 0.15 & 0.06 & 0.04 & 0.00 & 0.00 \\
\hline & $\mathrm{n}-\mathrm{C}_{4}$ & 0.50 & 0.30 & 0.14 & 0.09 & 0.00 & 0.00 \\
\hline & $\mathrm{i}-\mathrm{C}_{5}$ & 0.82 & 0.54 & 0.32 & 0.23 & 0.00 & 0.00 \\
\hline & $\mathrm{n}-\mathrm{C}_{5}$ & 0.71 & 0.43 & 0.25 & 0.16 & 0.00 & 0.00 \\
\hline & $\mathrm{C}_{6}$ & 0.50 & 0.33 & 0.24 & 0.16 & 0.00 & 0.00 \\
\hline & $\mathrm{C}_{7}$ & 0.88 & 0.77 & 0.74 & 0.67 & 0.00 & 0.00 \\
\hline & $\mathrm{C}_{8}$ & 3.34 & 2.98 & 2.81 & 2.63 & 0.24 & 0.34 \\
\hline & $\mathrm{C}_{9}$ & 5.90 & 5.82 & 5.88 & 5.83 & 1.87 & 2.11 \\
\hline & $\mathrm{C}_{10}$ & 17.65 & 18.42 & 18.88 & 19.07 & 13.12 & 13.97 \\
\hline & $\mathrm{C}_{11}$ & 25.52 & 26.66 & 26.76 & 27.40 & 27.46 & 28.53 \\
\hline & $\mathrm{C}_{12+}$ & 43.85 & 43.51 & 43.88 & 43.72 & 57.31 & 55.05 \\
\hline \multirow{2}{*}{\multicolumn{2}{|c|}{$\begin{array}{l}\text { Asphaltene content, wt. } \% \\
\text { Density }\left(30^{\circ} \mathrm{C}\right), \mathrm{g} / \mathrm{cm}^{3}\end{array}$}} & 3.61 & 3.48 & 3.12 & 2.82 & 3.55 & 3.04 \\
\hline & & 0.96 & 0.93 & 0.90 & 0.86 & 0.95 & 0.88 \\
\hline \multicolumn{2}{|c|}{ Viscosity $\left(30^{\circ} \mathrm{C}\right), \mathrm{mPa} \cdot \mathrm{s}$} & 783 & 461 & 242 & 129.78 & 586.8 & 218.97 \\
\hline
\end{tabular}

Table 2. The basic parameters of core samples used in this paper.

\begin{tabular}{cccccc}
\hline Core Number & Length, $\mathbf{c m}$ & Dimension, $\mathbf{c m}$ & Porosity, $\%$ & Permeability, mD & \multicolumn{1}{c}{ Marks } \\
\hline$\# 1$ & 25.21 & 2.53 & 21.09 & 363 & Used to study the \\
$\# 2$ & 25.16 & 2.52 & 21.03 & 359 & impact of flow rate \\
$\# 3$ & 25.18 & 2.49 & 21.07 & 360 & on threshold \\
$\# 4$ & 25.16 & 2.52 & 22.06 & 502 & pressure gradient \\
$\# 5$ & 25.05 & 2.50 & 23.58 & 946 & (TPG) measurement. \\
$\# 6$ & 25.01 & 2.51 & 20.84 & 324 & \\
$\# 7$ & 25.24 & 2.48 & 24.83 & 1465 & \\
$\# 8$ & 24.81 & 2.48 & 27.16 & 2765 & \\
$\# 9$ & 25.30 & 2.50 & 21.57 & 426 & Used to study the \\
$\# 10$ & 25.00 & 2.53 & 26.68 & 2465 & relationship between \\
$\# 11$ & 24.92 & 2.51 & 28.56 & 3621 & TPG and mobility. \\
$\# 12$ & 24.62 & 2.48 & 21.04 & 361 & \\
$\# 13$ & 25.29 & 2.52 & 27.37 & 2894 & \\
$\# 14$ & 24.81 & 2.49 & 28.61 & 3710 & \\
$\# 15$ & 24.80 & 2.52 & 21.16 & 382 & \\
$\# 16$ & 25.32 & 2.48 & 27.06 & 2695 & \\
$\# 17$ & 24.86 & 2.53 & 28.51 & 3580 & \\
\hline
\end{tabular}


Table 2. Cont.

\begin{tabular}{cccccc}
\hline Core Number & Length, cm & Dimension, cm & Porosity, $\%$ & Permeability, mD & Marks \\
\hline$\# 18$ & 25.07 & 2.49 & 19.37 & 92 & \\
$\# 19$ & 24.79 & 2.51 & 20.30 & 238 & \\
$\# 20$ & 25.38 & 2.50 & 21.10 & 367 & Used to determine \\
$\# 21$ & 24.67 & 2.48 & 22.92 & 647 & the critical viscosity \\
$\# 22$ & 25.22 & 2.51 & 23.63 & 976 & for the existence of \\
$\# 23$ & 25.09 & 2.49 & 24.85 & 1460 & TPG at a given \\
$\# 24$ & 25.26 & 2.50 & 26.41 & 2289 & permeability. \\
$\# 25$ & 24.96 & 2.51 & 27.52 & 3042 & \\
$\# 26$ & 24.75 & 2.48 & 28.49 & 3525 & \\
$\# 27$ & 25.19 & 2.49 & 21.09 & 362 & \\
$\# 28$ & 25.18 & 2.47 & 21.02 & 358 & \\
$\# 29$ & 25.21 & 2.52 & 21.05 & 360 & \\
$\# 30$ & 25.04 & 2.52 & 24.76 & 1452 & Used to study the \\
$\# 31$ & 25.00 & 2.51 & 26.37 & 2278 & flow characteristics \\
$\# 32$ & 25.19 & 2.50 & 21.05 & 362 & of heavy oil. \\
$\# 33$ & 25.17 & 2.48 & 21.03 & 358 & \\
$\# 34$ & 25.22 & 2.52 & 21.09 & 365 & \\
$\# 35$ & 25.07 & 2.51 & 24.62 & 1448 & \\
$\# 36$ & 24.97 & 2.50 & 26.28 & 2270 & \\
\hline
\end{tabular}

Table 3. The information of water used in this paper.

\begin{tabular}{ccc}
\hline \multicolumn{2}{c}{ Parameters } & Value \\
\hline & $\mathrm{Na}^{+}$and $\mathrm{K}^{+}$ & 3091.960 \\
& $\mathrm{Ca}^{2+}$ & 276.17 \\
$\mathrm{Mg}^{2+}$ & 156.68 \\
Composition, & $\mathrm{CO}_{3}{ }^{2-}$ & 11 \\
$\mathrm{mg} / \mathrm{L}$ & $\mathrm{HCO}_{3}{ }^{-}$ & 311.48 \\
& $\mathrm{SO}_{4}{ }^{2-}$ & 85.29 \\
& $\mathrm{Cl}^{-}$ & 5436.34 \\
& $\mathrm{TDS}$ & 9374.12 \\
\hline \multicolumn{2}{c}{ Density $\left(30^{\circ} \mathrm{C}\right), \mathrm{g} / \mathrm{cm}^{3}$} & 1.046 \\
\hline
\end{tabular}

\subsubsection{Rheology Test}

Rheological experiments were carried out by a Physica MCR301 rotary rheometer from Anton Paar (Graz, Austria). The viscosity of heavy oil samples was measured in a wide range of sheer rates of $0-50 \mathrm{~s}^{-1}$ by a plate-plate measurement system. The temperature was controlled by a Peltier plate with an accuracy of $0.01^{\circ} \mathrm{C}$. Figure 1 shows the schematic diagram of the Anton Paar rheometer and its plate-plate measuring system.

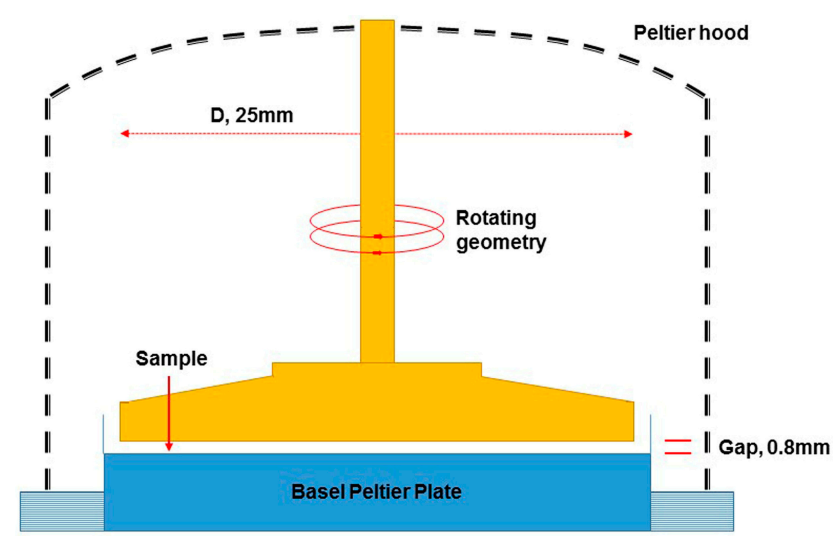

Figure 1. Schematic diagram of the rheometer and its plate-plate measuring system. 


\subsubsection{TPG Measurement and Its Critical Condition}

The schematic of the TPG measurment experiment is shown in Figure 2. The experimental procedure followed was:

1. Experimental devices were connected according to the flow chart.

2. The temperature of the thermotank was set to $30^{\circ} \mathrm{C}$, and the core with the saturated water was required to stand for at least $24 \mathrm{~h}$.

3. The heavy oil sample was used to displace the water in the core at a flow rate of $0.05 \mathrm{~mL} / \mathrm{min}$ after bypassing the oil column tube \#1. The displacing flow rate was increased to $0.5 \mathrm{~mL} / \mathrm{min}$ when the water cut at the outlet was lower than $2 \%$ until the volume of injected heavy oil sample reached ten times the pore volume (PV) of the core, and there was no water production.

4. The ISCO pump was stopped, and the height of the oil column in the oil column tube \#2 was lowered to about $5 \mathrm{~cm}$.

5. The oil column tube \#1 was put into use. The height of the oil column in the oil column tube \#1 was raised to the same height as that in the oil column tube \#2 by restarting the ISCO pump with the flow rate of $0.02 \mathrm{~mL} / \mathrm{min}$. The ISCO pump was stopped again, and this condition was kept for $24 \mathrm{~h}$.

6. The flow rate of $0.002 \mathrm{~mL} / \mathrm{min}$ was used to displace and the height of the oil column in the oil column tube \#1 increased gradually. The pressure gradient was the TPG of the heavy oil sample when the height of the oil column in the oil column tube $\# 2$ began to move.

In order to ensure that the accuracy of the TPG measurement experiment was not affected by the air, the relevant experimental devices, including the pipelines in the measurement system, were completely filled with the corresponding liquid.

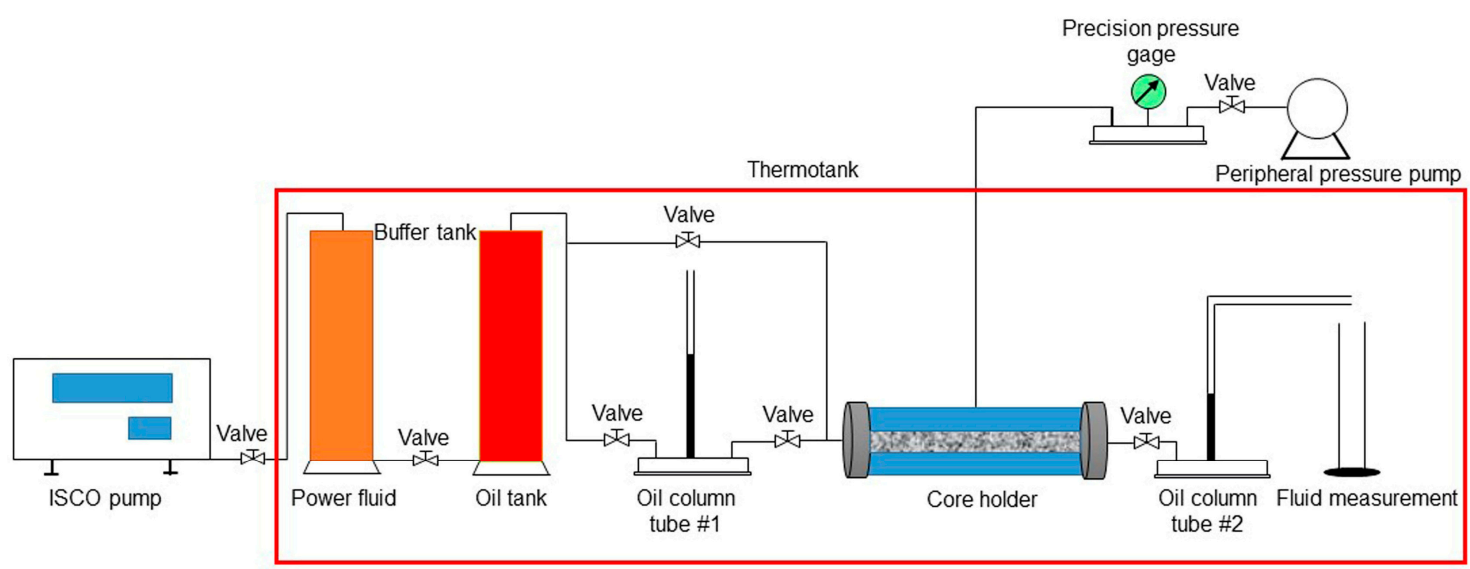

Figure 2. The schematic of the TPG measurement experiment.

Many factors, including viscosity and permeability, affect the TPG and its existence. The TPG exists under specific conditions, and an experiment to determine those critical conditions was necessary. The steps taken to identify the critical conditions were:

1. The TPG under the $k_{i}$ and $\mu_{j}$ was measured, where $k_{i}$ was the $i^{\text {th }}$ permeability, which started from $k_{1}$, and $\mu_{j}$ is the $j^{\text {th }}$ viscosity, which started from $\mu_{1}$.

2. If the TPG existed under the $k_{i}$ and $\mu_{j}$, a $\mu_{j+1}$ smaller than $\mu_{j}$ was used to replace $\mu_{j}$, and the TPG at the $k_{i}$ and $\mu_{j+1}$ was measured. If not, a $\mu_{j+1}$ larger than $\mu_{j}$ was used.

3. The selection of $\mu_{j}$ was repeated until two cases for the inexistence of the TPG and four cases for the existence of the TPG were obtained. A curve of the relationship between the TPGs greater than $0 \mathrm{MPa} / \mathrm{m}$ and the corresponding viscosity was drawn. The intercept of the fitting curve on 
the viscosity axis was considered to be the critical viscosity $\left(\mu_{c i}\right)$ at the $k_{i}$. Here, the TPG would be present for the specific permeability $k_{i}$ when the viscosity is higher than the critical viscosity $\left(\mu_{c i}\right)$. Otherwise, the TPG no longer existed.

4. The above steps were repeated until $N$ sets of permeability and the corresponding critical viscosities were obtained, where $N$ was determined by the requirements of the study.

To ensure the accuracy of experimental results, the variation of viscosity in each group was lower than $2 \mathrm{mPa} \cdot \mathrm{s}$ in the experiments. The experimental flow diagram of the critical viscosity for the existence of TPG at a given permeability is presented in Figure 3, where $r$ and $l$ are the numbers of groups with and without the TPG, separately.

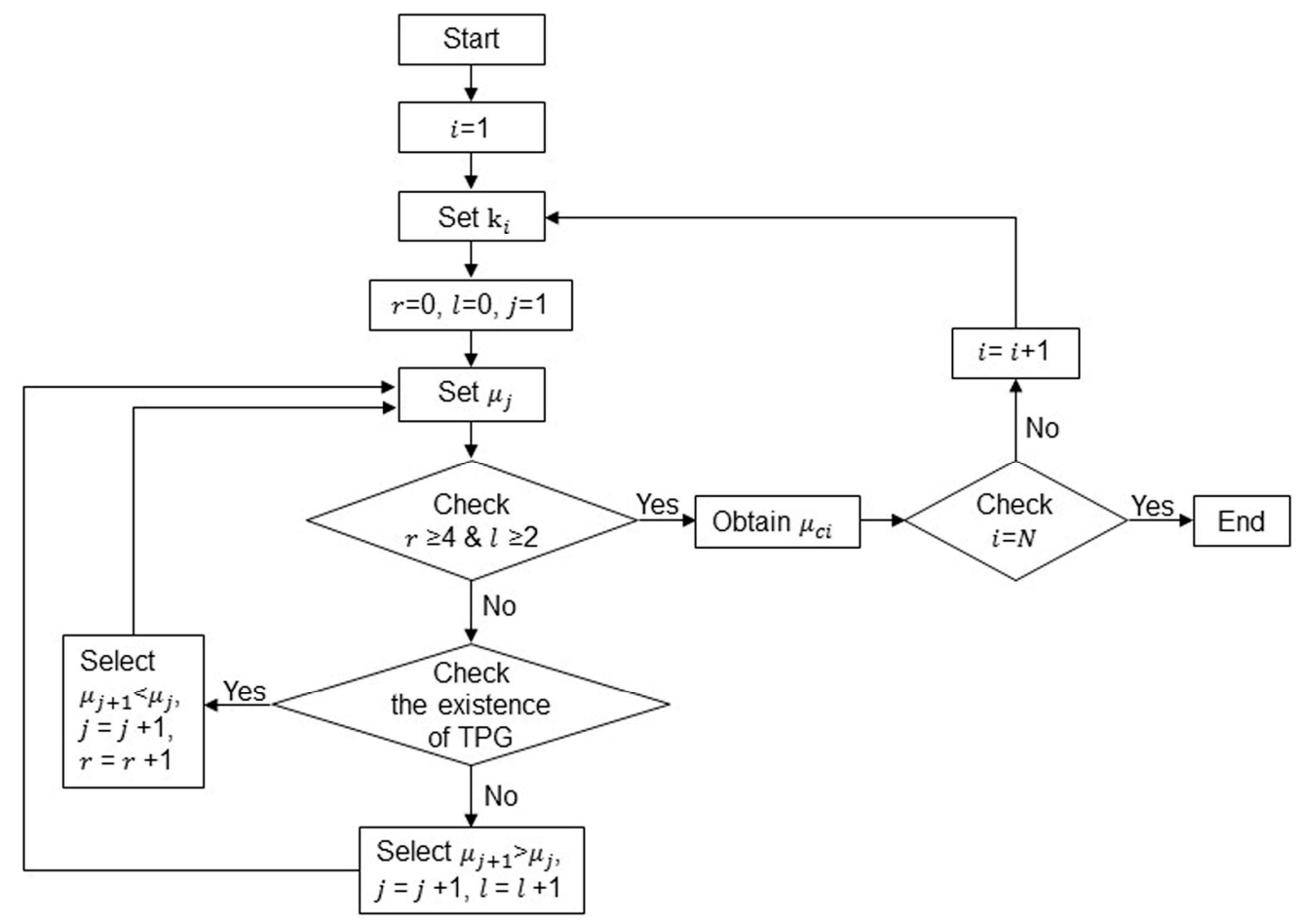

Figure 3. The experimental flow diagram of critical viscosity for the existence of the TPG at a given permeability.

\subsubsection{Flow Experiments}

Both the single-phase and oil-water two-phase flow experiments were conducted by the steady-state method to investigate the overall flow curve of the heavy oil shown in Figure 4 . For single-phase flow experiment, the core was saturated with the heavy oil sample only. The flow rate of the heavy oil samples were gradually set to $0.1,0.3,0.5,1,3$ and $5 \mathrm{~mL} / \mathrm{min}$. The pressure gradient and the corresponding flow rate were recorded for every flow rate when the pressure difference was stabilized and the flow rate of heavy oil sample at the inlet was the same as that at the outlet. After this, the relationship between pressure gradient and the corresponding flow rate was plotted. The oil-water two-phase flow experiment was different from the single-phase flow experiment. The core was saturated with the heavy oil sample and irreducible water in the same way as the process in TPG measurement experiment. The heavy oil sample and water at a ratio of 7:3 was used to displace. The total flow rate of heavy oil samples and water was gradually set to $0.1,0.3,0.5,1$ and $2 \mathrm{~mL} / \mathrm{min}$. The pressure gradient and the corresponding total flow rate were recorded for every total flow rate when the pressure difference was stabilized and the total flow rate of heavy oil sample and water at the inlet was the same as their total flow rates at the outlet. 


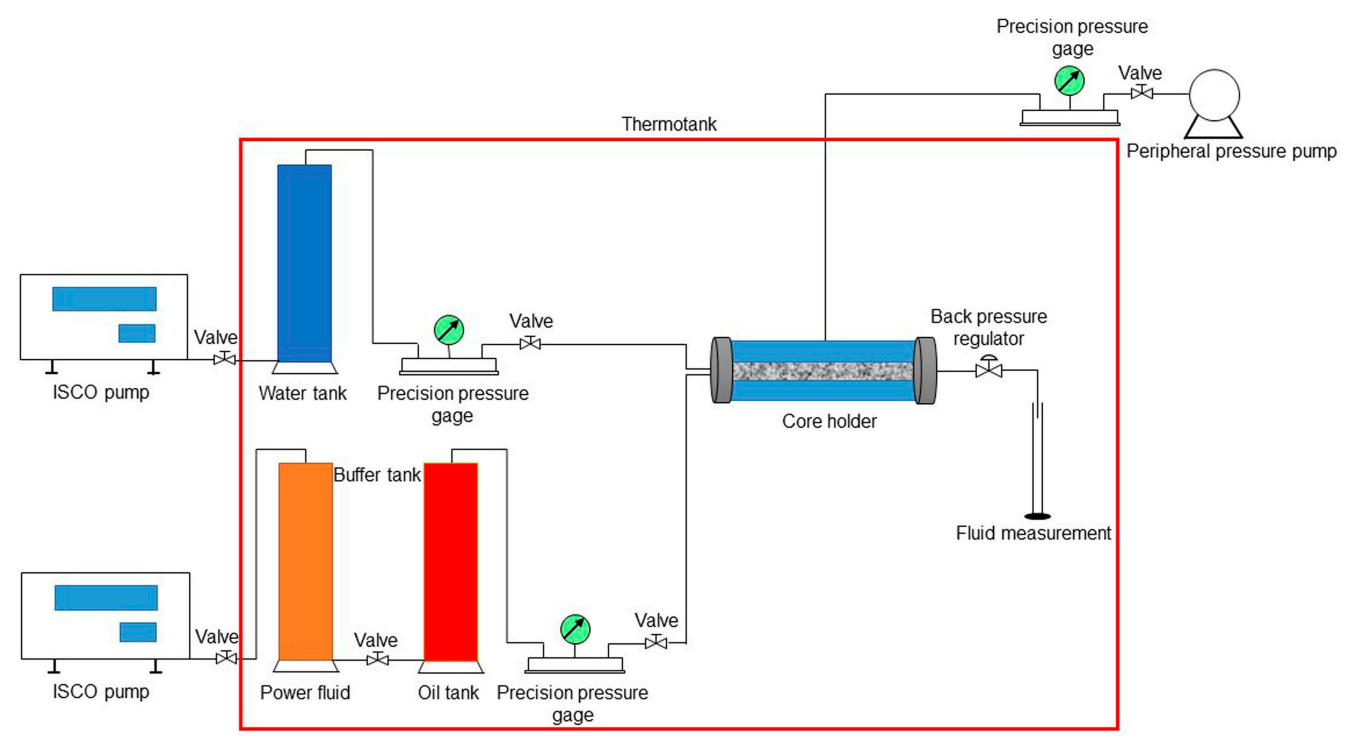

Figure 4. The schematic of the heavy oil flow experiment.

\subsection{Numerical Method}

\subsubsection{Corrected Darcy's Law}

The flow of heavy oil does not follow Darcy's law. The proposed correction to Darcy's law is $[23,57]$ :

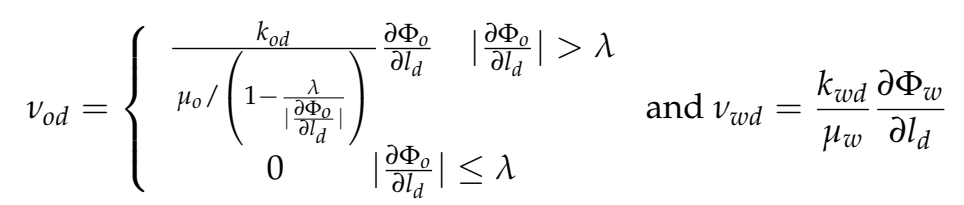

where $v_{o d}(d=1,2,3)$ are the oil velocities in the $l_{1}=x, l_{2}=y$ and $l_{3}=z$ directions in $\mathrm{m} / \mathrm{s} ; k_{o d}(d=1,2,3)$ are the oil permeabilities in $x, y$ and $z$ directions in $\mathrm{m}^{2}$; $\mu_{o}$ and $\mu_{w}$ are the viscosities of oil and water in Pa.s; $\lambda$ is the TPG in Pa/m; $\partial$ is a symbol used to denote partial derivatives; $\Phi_{o}=p_{o}-\rho_{o} g D$ and $\Phi_{w}=p_{w}-\rho_{w} g D$ in Pa; $p_{o}$ and $p_{w}$ are the pressures of the oil and water phase in $\mathrm{Pa} ; \rho_{o}$ and $\rho_{w}$ are the oil and water densities in $\mathrm{kg} / \mathrm{m}^{3} ; g$ is the gravitational acceleration in $\mathrm{m} / \mathrm{s}^{2} ; D$ is the vertical height in $\mathrm{m} ; v_{w d}(d=1,2,3)$ are the water velocities in $x, y$ and $z$ directions in $\mathrm{m} / \mathrm{s}$ and $k_{w d}(d=1,2,3)$ are the water permeabilities in $x, y$ and $z$ directions in $\mathrm{m}^{2}$. Equation (2) can be called the motion equation of the Bingham fluid.

The corrected oil viscosity is defined as:

$$
\mu_{\text {cod }}=\left\{\begin{array}{c}
\mu_{0} /\left(1-\frac{\lambda}{\left|\frac{\partial \Phi}{\partial l_{d}}\right|}\right) \quad\left|\frac{\partial \Phi}{\partial l_{d}}\right|>\lambda \\
\infty \quad\left|\frac{\partial \Phi}{\partial l_{d}}\right| \leq \lambda
\end{array}\right.
$$

where $\mu_{c o d}(d=1,2,3)$ are the corrected oil viscosities in the $x, y$ and $z$ directions in Pa.s.

\subsubsection{Flow Model}

The basic assumptions for the numerical method are as follows:

1. The corrected Darcy's law of Equation (2) was applied.

2. The model was 3D with two phases (the oil and water phases).

3. The water component existed only in the water phase, which did not exchange its mass with the oil phase. 
4. The reservoir rock was compressible and anisotropic, while the fluid was compressible.

5. The effects of the capillary force and gravity were taken into account.

According to the conservation of mass, we obtained the continuity equations by combing mass with the above motion equation.

For the oil component $[58,59]$ :

$$
\begin{gathered}
\frac{\partial}{\partial x}\left[\rho_{o s} \frac{k_{a} k_{r o}}{B_{0} r_{c o 1}}\left(\frac{\partial p_{o}}{\partial x}-\rho_{o g} \frac{\partial D}{\partial x}\right)\right]+\frac{\partial}{\partial y}\left[\rho_{o s} \frac{k_{a} k_{r o}}{B_{o} \mu_{c 02}}\left(\frac{\partial p_{o}}{\partial y}-\rho_{o} g \frac{\partial D}{\partial y}\right)\right] \\
+\frac{\partial}{\partial z}\left[\rho_{o s} \frac{k_{a} k_{r o}}{B_{o} \mu_{c o 3}}\left(\frac{\partial p_{o}}{\partial z}-\rho_{o g} g \frac{\partial D}{\partial z}\right)\right]+q_{o}=\frac{\partial}{\partial t}\left(\rho_{o s} \frac{\phi S_{o}}{B_{0}}\right)
\end{gathered}
$$

For the water component:

$$
\begin{gathered}
\frac{\partial}{\partial x}\left[\rho_{w s} \frac{k_{a} k_{r w}}{B_{B_{w}} \mu_{w}}\left(\frac{\partial p_{w}}{\partial x}-\rho_{w} g \frac{\partial D}{\partial x}\right)\right]+\frac{\partial}{\partial y}\left[\rho_{w s} \frac{k_{a} k_{r w}}{B_{w w} \mu_{w}}\left(\frac{\partial p_{w}}{\partial y}-\rho_{w} g \frac{\partial D}{\partial y}\right)\right] \\
+\frac{\partial}{\partial z}\left[\rho_{w s} k_{a} k_{r w}\left(\frac{\partial p_{w w}}{\partial z}-\rho_{w s} g \frac{\partial D}{\partial z}\right)\right]+q_{w}=\frac{\partial}{\partial t}\left(\rho_{w w} \frac{\phi S_{w}}{B_{w w}}\right)
\end{gathered}
$$

In the two equations above, $\rho_{o s}$ and $\rho_{w s}$ are the densities of oil and water in the ground standard conditions in $\mathrm{kg} / \mathrm{m}^{3} ; k_{a}$ is the absolute permeability of porous media in $\mathrm{m}^{2} ; k_{r o}$ and $k_{r w}$ are the relative permeabilities of oil and water in fraction; $q_{o}$ and $q_{w}$ are the mass flow rates of oil and water in the ground standard conditions in $\mathrm{kg} / \mathrm{s} ; B_{0}$ and $B_{w}$ are the oil and water formation volume factor in $\mathrm{m}^{3} / \mathrm{m}^{3}$; and $S_{o}$ and $S_{w}$ are the oil saturation and water saturation in fraction.

In addition to the two continuity differential equations, there are the following auxiliary equations and state equations. The auxiliary equations included:

$$
\begin{gathered}
S_{o}+S_{w}=1 \\
p_{w}=p_{o}-p_{c o w}\left(S_{w}\right)
\end{gathered}
$$

where $p_{\text {cow }}$ is the water-oil capillary pressure in a two-phase system in $\mathrm{Pa}$, which is a function of water saturation. The state equations are as follows:

$$
\begin{gathered}
k_{r o}=k_{r o}\left(S_{w}\right) \\
k_{r w}=k_{r w}\left(S_{w}\right) \\
\mu_{c o d}=\mu_{c o d}(\lambda, \nabla \Phi) \\
\rho_{o}=\rho_{o}\left(p_{o}\right) \\
\rho_{w}=\rho_{w}\left(p_{w}\right) \\
\phi=\phi\left(P_{r}\right)
\end{gathered}
$$

where $P_{r}$ is the reservoir pressure in Pa.

\subsubsection{IMPES}

The difference equation of Equation (4) was given as follows: 


$$
\begin{gathered}
\frac{m_{o x i+\frac{1}{2}, j, k} \frac{\Phi_{o i+1, j, k}^{n+1}-\Phi_{o i, j, k}^{n+1}}{0.5\left(\Delta x_{i+1}+\Delta x_{i}\right)}-m_{o x i-\frac{1}{2}, j, k} \frac{\Phi_{o i, j, k}^{n+1}-\Phi_{o i-1, j, k}^{n+1}}{0.5\left(\Delta x_{i}+\Delta x_{i-1}\right)}}{\Delta x_{i}} \\
+\frac{m_{o y i, j+\frac{1}{2}, k} \frac{\Phi_{o i, j+1, k}^{n+1}-\Phi_{o i, j, k}^{n+1}}{0.5\left(\Delta y_{i+1}+\Delta y_{i}\right)}-m_{o y i, j-\frac{1}{2}, k} \frac{\Phi_{o i, j, k}^{n+1}-\Phi_{o i, j-1, k}^{n+1}}{0.5\left(\Delta y_{i}+\Delta y_{i-1}\right)}}{+\frac{m_{o z i, j, k+\frac{1}{2}} \frac{\Phi_{o i, j, k+1}^{n+1} \Phi_{o i, j, k}^{n+1}}{0.5\left(\Delta z_{i+1}+\Delta z_{i}\right)}-m_{o z i, j, k-\frac{1}{2}} \frac{\Phi_{o i, j, k}^{n+1}-\Phi_{o i, j, k-1}^{n+1}}{0.5\left(\Delta z_{i}+\Delta z_{i-1}\right)}}{\Delta z_{i}}} \\
+q_{o i, j, k}=\frac{1}{\Delta t}\left[\left(\frac{\phi \rho_{o} s_{o}}{B_{o}}\right)_{i, j, k}^{n+1}-\left(\frac{\phi \rho_{o} s_{o}}{B_{o}}\right)_{i, j, k}^{n}\right]
\end{gathered}
$$

where the subscripts $i, j, k$ are the coordinate markers in the grid; the superscript $\mathrm{n}$ is the time marker; $\Delta x, \Delta y$ and $\Delta z$ are the step length $(\mathrm{m})$ in the direction of $x, y$ and $z$; $m_{o x}=\frac{k_{a} k_{r o}}{B_{o} \mu_{c o 1}}, m_{o y}=\frac{k_{a} k_{r o}}{B_{o} \mu_{c o 2}}$, and $m_{o z}=\frac{k_{a} k_{r o}}{B_{o} \mu_{c o 3}}$ in $\mathrm{m}^{2} / \mathrm{Pa} \cdot \mathrm{s} . \mu_{c o d}$ can be calculated by the Equation (3) at each time step. The difference equation of Equation (5) is similar to the Equation (14) and is no longer listed in detail here.

In this work, these equations were solved by the IMPES with the auxiliary capillary and saturation equations under the boundary and initial conditions. More details can be found in [60]. Finally, production, pressure and oil saturation distribution were obtained.

\section{Results and Discussion}

\subsection{Rheology of Heavy Oil}

The rheological curves of heavy oil samples at different temperatures are shown in Figure 5. The relationship between a shear rate and sheer stress was linear, but the lines with the correlation a coefficient of up to 0.96 did not pass through the origin of the coordinate axes. This phenomenon was the same for the Bingham fluid. The yield stress of the heavy oil decreased with an increase in temperature, while the shear stress at a low temperature was higher than that at a high temperature under the same shear rate. Considering oil sample \#1, the shear stress was $42.2 \mathrm{~Pa}$ at $30{ }^{\circ} \mathrm{C}$, which was nearly five times greater than that at $70{ }^{\circ} \mathrm{C}$ with the same shear rate of $50 \mathrm{~s}^{-1}$.
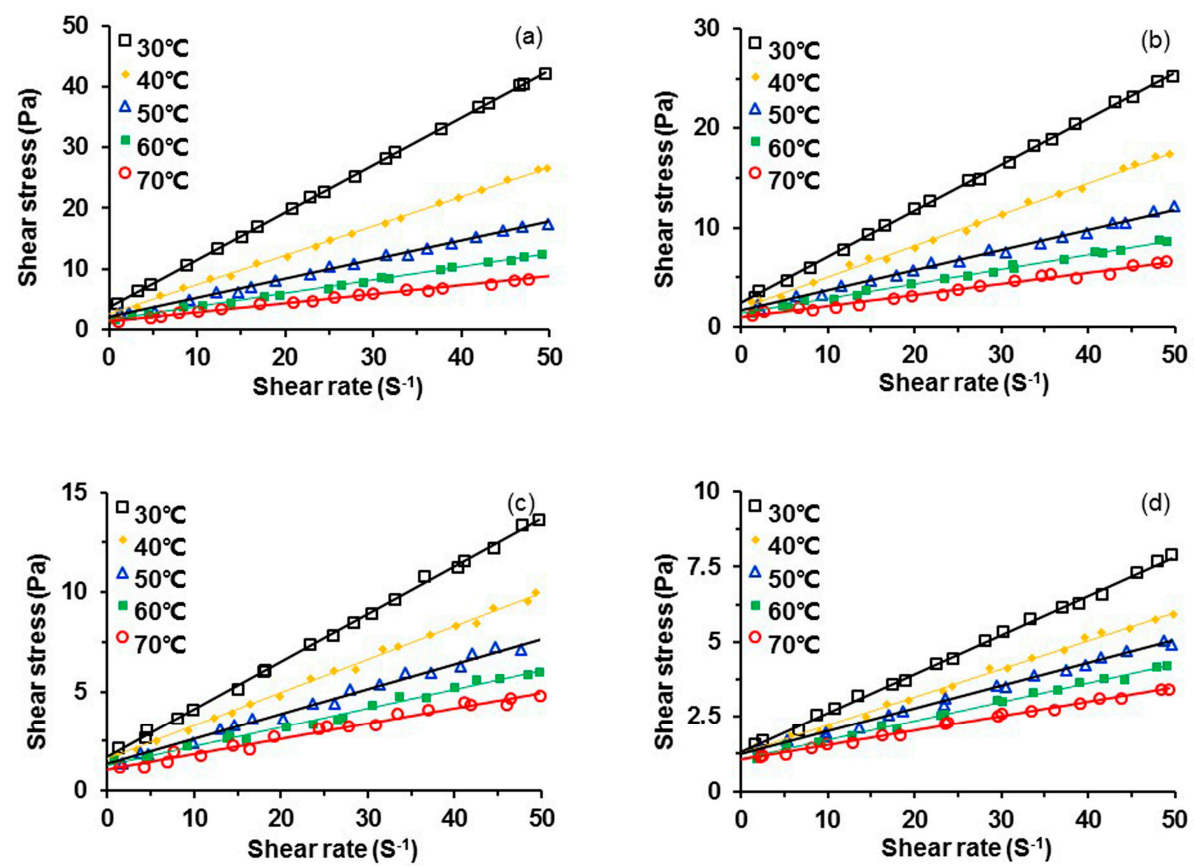

Figure 5. Cont. 

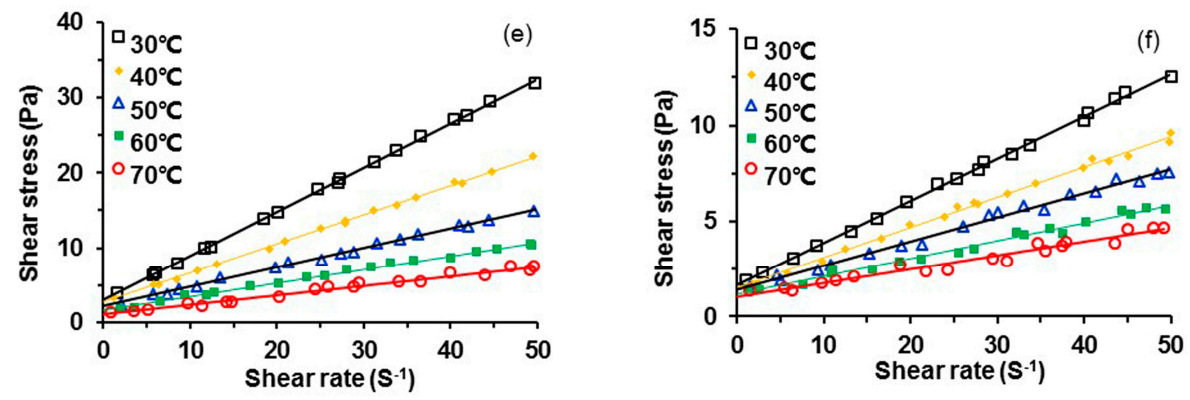

Figure 5. Rheological curves for: (a) oil sample \#1; (b) oil sample \#2; (c) oil sample \#3; (d) oil sample \#4; (e) oil sample \#5; and (f) oil sample \#6.

The viscosity-temperature curves of heavy oil samples are shown in Figure 6. The viscosity of the heavy oil showed a strong temperature sensitivity. The findings demonstrated that the viscosity of the heavy oil samples decreased significantly with an increase in temperature below $50{ }^{\circ} \mathrm{C}$. The change in viscosity was great when the temperature was low, while the decrease in viscosity changed slowly when the temperature was above $50^{\circ} \mathrm{C}$. The Arrhenius equation was applied to quantify the relationship. It is the most accepted model to correlate the temperature dependence of the viscosity of a fluid $[10,11,61]$ :

$$
\mu_{0}(T)=A \exp \left[E_{a} /(R T)\right]
$$

where $\mu_{0}(T)$ is the zero-shear viscosity in Pa.s; $T$ is the absolute temperature in $K ; A=\mu_{0}(T \rightarrow \infty)$ is a material constant in Pa.s; $E_{a}$ is the fluid-dependent activation energy in $\mathrm{J} / \mathrm{mol}$; and $R$ is the universal gas constant in $8.314 \mathrm{~J} / \mathrm{mol} / \mathrm{K}$. As the zero-shear viscosity in Equation (15) was very difficult to obtain from the experiment, an apparent viscosity was used to replace it $[62,63]$, and Equation (15) was rewritten as [7,8]:

$$
\ln \frac{\mu(T)}{\mu\left(70^{\circ} \mathrm{C}\right)}=\frac{E}{R}\left[\left(\frac{1}{T}-\frac{1}{343.15}\right)\right]
$$

where $\mu(T)$ is the apparent viscosity at the absolute temperature $T$ in $\mathrm{Pa} \cdot \mathrm{s} ; E$ is the apparent activation energy in $\mathrm{J} / \mathrm{mol}$; and $\mu\left(70^{\circ} \mathrm{C}\right)$ is the apparent viscosity at $70^{\circ} \mathrm{C}$ chosen as the reference temperature in the study in Pa.s.

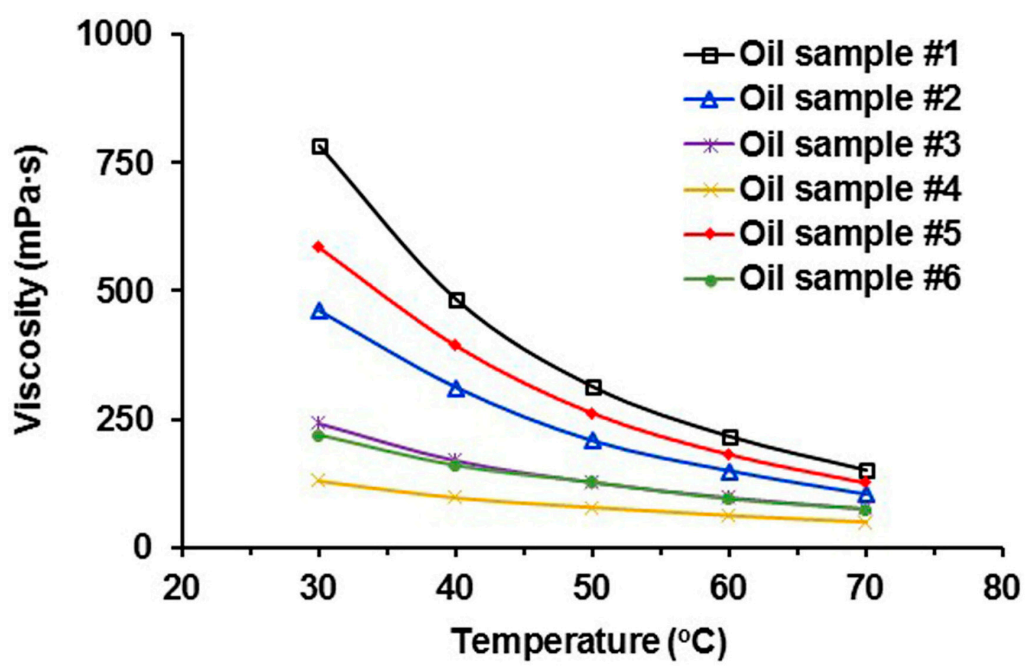

Figure 6. Viscosity-temperature curves of heavy oil samples.

The plots of $\ln \frac{\mu(T)}{\mu\left(70^{\circ} \mathrm{C}\right)}$ against $\frac{1}{R}\left(\frac{1}{T}-\frac{1}{343.15}\right)$ result in two straight lines with the slopes of $E$, which is the apparent activation energy of heavy oil samples (Figure 7). The correlation coefficients of 
the line fitting curves in each temperature interval were more than 0.98 , illustrating that the curves conformed to the Arrhenius equation.

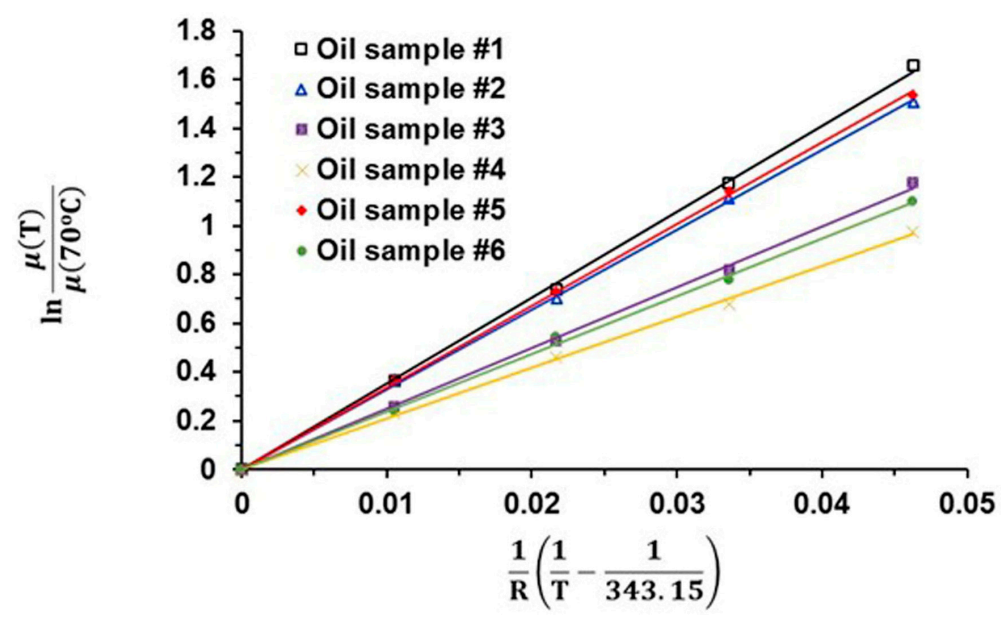

Figure 7. Plots in terms of the Arrhenius equation for heavy oil samples.

The impact of asphaltene content on heavy oil rheology can be seen by comparing Figure $5 \mathrm{e}, \mathrm{f}$. The shear stress decreased with a decrease in asphaltene content under the same shear rate and the same temperature. The shear stress of oil sample \#5 with $3.55 \mathrm{wt}$. \% asphaltene was $32 \mathrm{~Pa}$ at $30{ }^{\circ} \mathrm{C}$, which was nearly three times greater than that of oil sample \#6 with $3.04 \mathrm{wt}$. \% asphaltene at $30^{\circ} \mathrm{C}$ with the same shear rate of $50 \mathrm{~s}^{-1}$. The influence of asphaltene content on the viscosity of heavy oil can also be obtained from Figure 6. The viscosity of oil sample \#5 was $586.8 \mathrm{mPa} \cdot \mathrm{s}$, which was double than that of oil sample $\# 6$ at $30{ }^{\circ} \mathrm{C}$. This is due to the interaction force between various molecules because they increase as the asphaltene content rises, resulting in an easier asphaltene aggregation and a stronger network structure $[7,8,19,64]$.

\subsection{Threshold Pressure Gradient (TPG)}

\subsubsection{Impact of Flow Rate on TPG Measurement}

The TPG at different flow rates were measured to study the impact of flow rate on TPG measurement, and the results are presented in the Table 4 . It can be seen from Table 4 that the TPG remained the same when the flow rate was lower than $0.003 \mathrm{~mL} / \mathrm{min}$. However, TPG increased with an increase in flow rate when the flow rate is higher than $0.003 \mathrm{~mL} / \mathrm{min}$.

Table 4. The TPG measured at the different flow rate.

\begin{tabular}{cccccc}
\hline \multirow{3}{*}{ Flow Rate, $\mathbf{m L}$ /min } & \multicolumn{5}{c}{ Threshold Pressure Gradient, MPa/m } \\
\cline { 2 - 6 } & Core Sample: \#1 & Core Sample: \#2 & Core Sample: \#3 & Core Sample: \#4 & Core Sample: \#5 \\
\cline { 2 - 6 } & Oil Sample: \#1 & Oil Sample: \#2 & Oil Sample: \#3 & Oil Sample: \#4 & Oil Sample: \#5 \\
\hline 0.001 & 0.00127 & 0.00110 & 0.00087 & 0.00114 & 0.00092 \\
0.002 & 0.00127 & 0.00110 & 0.00087 & 0.00114 & 0.00092 \\
0.003 & 0.00127 & 0.00110 & 0.00087 & 0.00114 & 0.00092 \\
0.004 & 0.00133 & 0.00124 & 0.00092 & 0.00126 & 0.00099 \\
0.005 & 0.00142 & 0.00140 & 0.00102 & 0.00134 & 0.00109 \\
0.006 & 0.00164 & 0.00146 & 0.00103 & 0.00150 & 0.00114 \\
0.008 & 0.00171 & 0.00158 & 0.00108 & 0.00162 & 0.00121 \\
0.010 & 0.00186 & 0.00168 & 0.00114 & 0.00174 & 0.00128 \\
\hline
\end{tabular}

We obtained this result whether in the case of the same core and different oils or in the case of the same oil and different cores. The real TPG should be a quantification in the specific situation. 
The main reason for the change in the measured TPG at different flow rate was that the rapidly elevated pressure at the inlet of the core resulted in the measured TPG greater than the real TPG when the displacement flow rate exceeded the flow rate of $0.003 \mathrm{~mL} / \mathrm{min}$. Therefore, we considered $0.003 \mathrm{~mL} / \mathrm{min}$ as the critical flow rate in the TPG measurement experiment. In contrast, the TPG measured at smaller flow rate will be more accurate. However, a small flow will also lead to more time needed in the TPG measurement experiment. Finally, we selected the flow rate of $0.002 \mathrm{~mL} / \mathrm{min}$ for the TPG measurement experiment.

\subsubsection{Relationship between TPG and Mobility}

The TPG measurement results of heavy oil are provided in Table 5 . The table reveals that the TPG of heavy oil increased with an increase in viscosity when the permeability was the same. It increased as permeability decreased for the same heavy oil. Dong et al. [23] observed a similar behavior. This was attributed to the fact that the migration of heavy oil was influenced by the properties of fluid and porous media [31]. A larger pressure gradient was required to create the shear deformation of the heavy oil for the flow of heavy oil with a higher viscosity. Moreover, the flow resistance increased as the diameter of the pores and throats in addition to the permeability of the core decreased, which resulted in a difficult flow in the flow process of heavy oil [19]. Considering both the effects of heavy oil viscosity and permeability of the core on the TPG of heavy oil, we applied the mobility to calculate the TPG of heavy oil, which is defined as:

$$
M=\frac{k_{a}}{\mu_{0}}
$$

where $M$ is the mobility in $\mathrm{mD} / \mathrm{mPa} \cdot \mathrm{s}$. A power-law relationship between the TPG and the mobility was obtained (Figure 8), which can be written as:

$$
\lambda=0.001 M^{-0.365}
$$

Figure 8 indicates that the TPG decreased with an increase in mobility and declined even more when the mobility was lower than $5.30 \mathrm{mD} / \mathrm{mPa} \cdot \mathrm{s}$. The decline rate of the TPG decreased with the increasing mobility and the TPG dropped to $0.00026 \mathrm{MPa} \mathrm{m}^{-1}$ when the mobility was $27.54 \mathrm{mD} / \mathrm{mPa} \cdot \mathrm{s}$. It can be concluded that the TPG may disappear with an increase in mobility.

Table 5. TPG measurement results of the heavy oil.

\begin{tabular}{ccccc}
\hline Core & Permeability, $\mathbf{m D}$ & Oil Sample & Viscosity, $\mathbf{m P a} \cdot \mathbf{s}$ & TPG, $\mathbf{M P a} / \mathbf{m}$ \\
\hline$\# 6$ & 324 & $\# 1$ & 783 & 0.00135 \\
$\# 7$ & 1465 & $\# 1$ & 783 & 0.00083 \\
$\# 8$ & 2765 & $\# 1$ & 783 & 0.00070 \\
$\# 9$ & 426 & $\# 2$ & 461 & 0.00104 \\
$\# 10$ & 2465 & $\# 2$ & 461 & 0.00049 \\
$\# 11$ & 3621 & $\# 2$ & 461 & 0.00046 \\
$\# 12$ & 361 & $\# 3$ & 242 & 0.00083 \\
$\# 13$ & 2894 & $\# 3$ & 242 & 0.00045 \\
$\# 14$ & 3710 & $\# 3$ & 242 & 0.00042 \\
$\# 15$ & 382 & $\# 4$ & 130 & 0.00075 \\
$\# 16$ & 2695 & $\# 4$ & 130 & 0.00034 \\
$\# 17$ & 3580 & $\# 4$ & 130 & 0.00026 \\
\hline
\end{tabular}




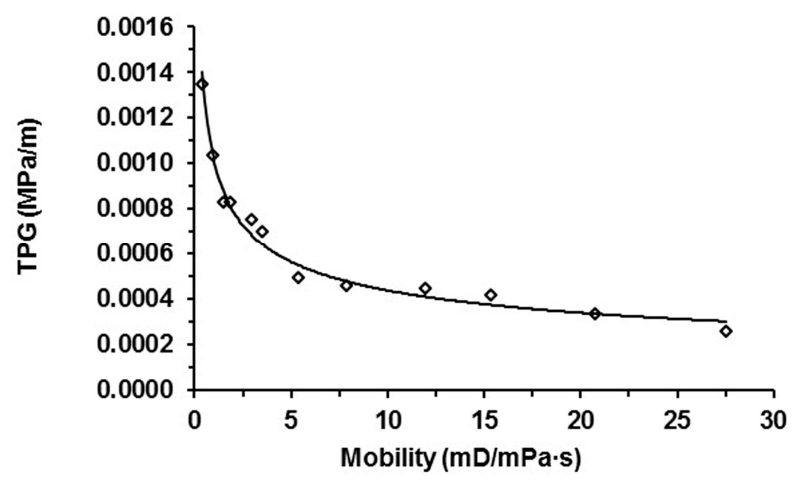

Figure 8. A power-law relationship between the TPG and mobility of heavy oil.

For a given permeability, the decrease in viscosity can lead to an increase of mobility and the disappearance in TPG. The critical viscosity for the existence of TPG is shown in Figure 9, above which the TPG existed. Otherwise, the TPG no longer existed. The critical viscosity increased and the growth rates tended to be relatively slow with an increase in permeability. Furthermore, the critical viscosity for Bohai Bay oilfield with the permeability range of $50-4000 \mathrm{mD}$ was $42-54 \mathrm{mPa} \cdot \mathrm{s}$. There was a TPG when the viscosity and permeability values were in the upper area. Otherwise, the TPG fell to zero.

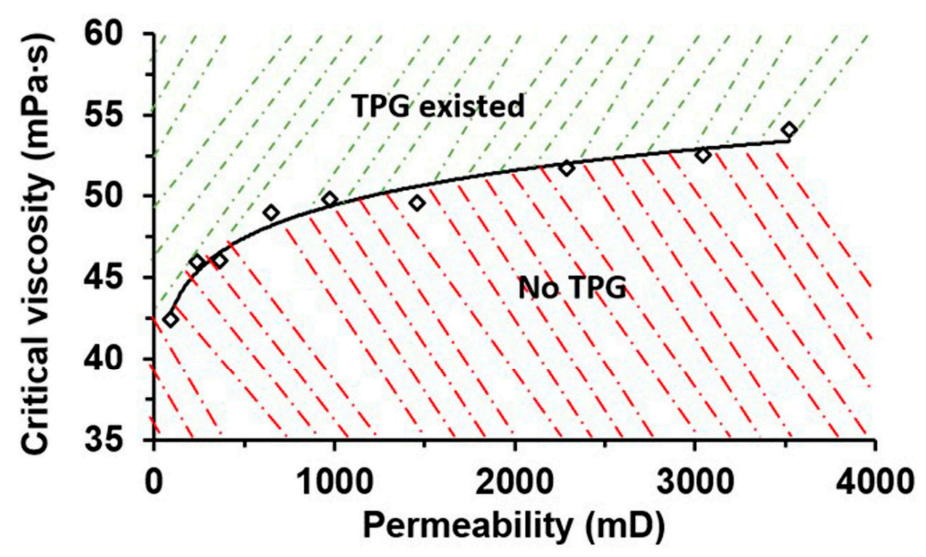

Figure 9. The critical viscosity for a given permeability, above which the TPG existed. Otherwise, the TPG no longer existed.

\subsection{Flow Characteristics of Heavy Oil in Porous Media}

The single-phase and oil-water two-phase flow experiment results and the curve fittings are presented separately in Figures 10 and 11. However, the TPG could not be obtained from the flow experiment due to that the pressure difference was very small when the heavy oil samples began to flow and could not be accurately measured by the pressure gauge, but the pseudo TPG can be determined from the interception of straight lines on the pressure gradient axis rather than direct measurement by the pressure gauge [27]. It can be used to show the difficulty of fluid flow as the TPG, but it cannot replace the TPG measured by micro-flow method with higher accuracy for the Bingham fluid. The pressure gradient increased with a rise in the flow rate. The relationship was basically a straight line and did not pass through the origin of the coordinate axes. It showed that heavy oil began to flow through porous media when displacement pressure gradient was larger than the pseudo TPG. These results reflect what is expected with Bingham fluid and non-Newtonian flow. Liu et al. [19] and Pang et al. [31] also reported this type of the flow behavior of heavy oil. From Figures 10 and 11, it can be seen that the pseudo TPG decreased with an increase in mobility in a similar way to the TPG. Figures 10a and 11a indicate that the pressure gradient tended to increase with an increase in the 
viscosity of the heavy oil for a given flow rate and permeability. In Figures $10 \mathrm{~b}$ and $11 \mathrm{~b}$, the pressure gradient increased with a decrease in permeability for a given flow rate and viscosity. Therefore, it can be concluded that the viscosity and permeability had significant impact on the flow characteristics of heavy oil. In the case of similar permeability and crude oil viscosity, it was obviously seen by comparing Figures 10 and 11 that the pseudo TPG in the oil-water two-phase flow is lower than that in the single-phase flow, while the pressure gradient at the same flow rate was of the same situation of the pseudo TPG. This is mainly due to the fact that the viscosity of the fluid with a high-water saturation during the oil-water two-phase flow process is lower than that of the heavy oil during the single-phase flow process, which is equivalent to diluting the heavy oil, so the pseudo TPG declines and the flow becomes easier [65].
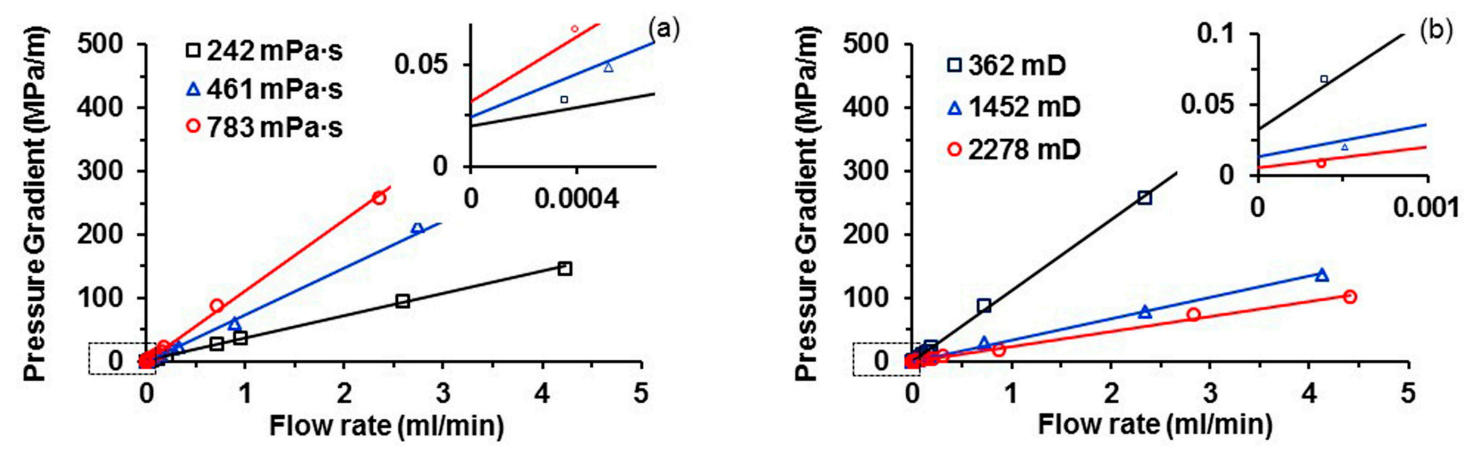

Figure 10. Single-phase flow curves of heavy oil: (a) at different viscosities, $k=362 \mathrm{mD}$; and (b) at different permeabilities, $\mu_{0}=783 \mathrm{mPa} \cdot \mathrm{s}$.
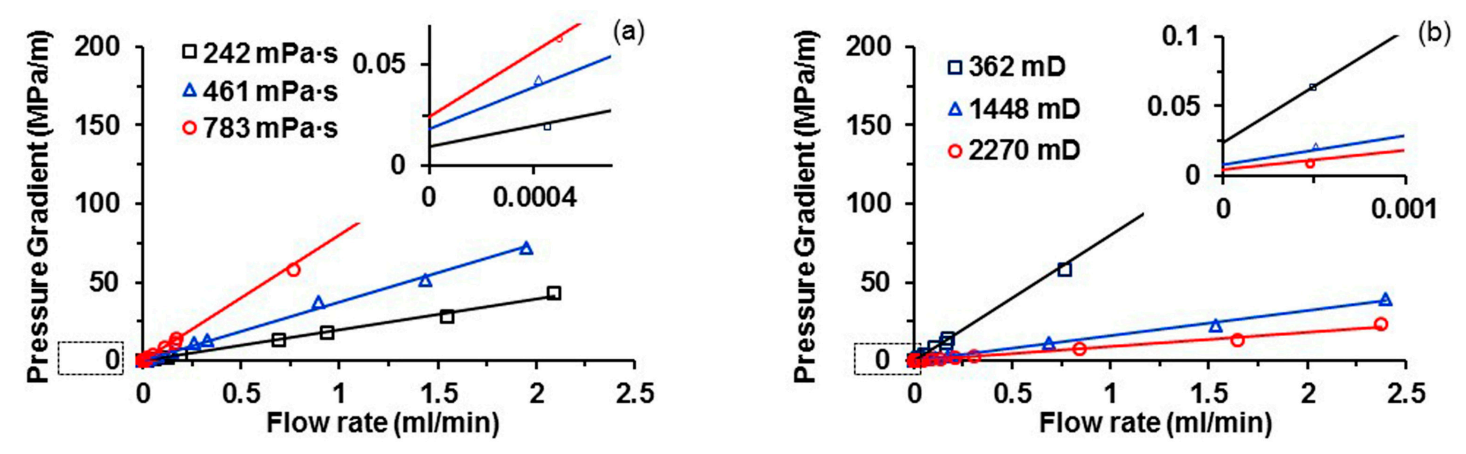

Figure 11. Oil-water two-phase flow curves of heavy oil: (a) at different viscosities, $k=362 \mathrm{mD}$; and (b) at different permeabilities, $\mu_{0}=783 \mathrm{mPa} \cdot \mathrm{s}$.

\subsection{Simulation}

\subsubsection{Validation}

Validation with Darcy's flow was carried out by simulating a case, where some data was obtained from SPE 21221 [66]. Its main information is provided in Tables 6-8 and Figure 12. The simulation results of ECLIPSE V2013.1 and CMG V2012 software were used to validate against our designed simulator because they are two commonly-used, recognized and authoritative numerical reservoir simulators. The comparison result of the pressure difference, oil production, water production, water cut, cumulative oil production and oil recovery are shown in Figure 13. From this figure, it is evident that the simulation result of our designed simulator was very close to ECLIPSE V2013.1 and CMG V2012 software findings. At 1500 days, the difference of cumulative oil production was only $0.50 \%$ and $0.74 \%$. Thus, the validation with Darcy flow was confirmed, and the simulator demonstrated a high reliability. 
Table 6. Reservoir data and initial conditions of the case used to validate the designed simulator.

\begin{tabular}{ccccccccc}
\hline Layer & $\begin{array}{c}\text { Thickness } \\
\boldsymbol{\Delta} \boldsymbol{z}, \mathbf{m}\end{array}$ & $\begin{array}{c}\text { Depth to } \\
\text { Center of } \\
\text { Layer, } \mathbf{m}\end{array}$ & $\begin{array}{c}\text { Horizontal } \\
\text { Permeability, } \\
\mathbf{m D}\end{array}$ & $\begin{array}{c}\text { Vertical } \\
\text { Permeability, } \\
\mathbf{m D}\end{array}$ & $\begin{array}{c}\text { Porosity, } \\
\text { Fraction }\end{array}$ & $\begin{array}{c}\text { Initial } \\
\text { Pressure, } \\
\mathbf{M P a}\end{array}$ & $\begin{array}{c}\text { Initial oil } \\
\text { Saturation, } \\
\text { Fraction }\end{array}$ & $\begin{array}{c}\text { Initial Water } \\
\text { Saturation, } \\
\text { Fraction }\end{array}$ \\
\hline 1 (top) & 6.096 & 1097.280 & 300 & 30 & 0.2 & 24.822 & 0.711 & 0.289 \\
2 & 6.096 & 1103.376 & 300 & 30 & 0.2 & 24.877 & 0.652 & 0.348 \\
3 & 6.096 & 1109.472 & 300 & 30 & 0.2 & 24.932 & 0.527 & 0.473 \\
4 & 6.096 & 1115.568 & 300 & 30 & 0.2 & 24.981 & 0.351 & 0.649 \\
5 & 9.144 & 1123.188 & 300 & 30 & 0.2 & 25.050 & 0.131 & 0.869 \\
6 (bottom) & 15.240 & 1135.380 & 300 & 30 & 0.2 & 25.167 & 0.000 & 1.000 \\
\hline
\end{tabular}

Table 7. Fluid property, rock property and production data of the case.

\begin{tabular}{|c|c|}
\hline Parameters & Value \\
\hline Stock tank oil density, $\mathrm{g} / \mathrm{cm}^{3}$ & 0.721 \\
\hline Initial oil viscosity, $\mathrm{mPa} \cdot \mathrm{s}$ & 0.95 \\
\hline Oil compressibility, $\mathrm{MPa}^{-1}$ & $1.45 \times 10^{-3}$ \\
\hline Oil formation volume factor & 1.11 \\
\hline Initial water density, $\mathrm{g} / \mathrm{cm}^{3}$ & 0.995 \\
\hline Initial water viscosity, $\mathrm{mPa} \cdot \mathrm{s}$ & 0.96 \\
\hline Water compressibility, $\mathrm{MPa}^{-1}$ & $4.35 \times 10^{-4}$ \\
\hline Water formation volume factor & 1.014 \\
\hline Rock compressibility, $\mathrm{MPa}^{-1}$ & $5.80 \times 10^{-4}$ \\
\hline Bottom hole pressure of injection well, $\mathrm{MPa}$ & 25.512 \\
\hline Minimum bottom hole pressure of production well, $\mathrm{MPa}$ & 10.343 \\
\hline Liquid rate of production well, $\mathrm{m}^{3} / \mathrm{d}$ & 477 \\
\hline
\end{tabular}

Table 8. Relative permeabilities and capillary pressures used in the case.

\begin{tabular}{cccc}
\hline$S_{w}$ & $k_{r w}$ & $k_{r o}$ & $p_{c o w}, M P a$ \\
\hline 0.2200 & 0.0000 & 1.0000 & 0.0434 \\
0.3000 & 0.0700 & 0.4000 & 0.0248 \\
0.4000 & 0.1500 & 0.1250 & 0.0186 \\
0.5000 & 0.2400 & 0.0649 & 0.0155 \\
0.6000 & 0.3300 & 0.0048 & 0.0124 \\
0.8000 & 0.6500 & 0.0000 & 0.0062 \\
0.9000 & 0.8300 & 0.0000 & 0.0031 \\
1.0000 & 1.0000 & 0.0000 & 0.0000 \\
\hline
\end{tabular}

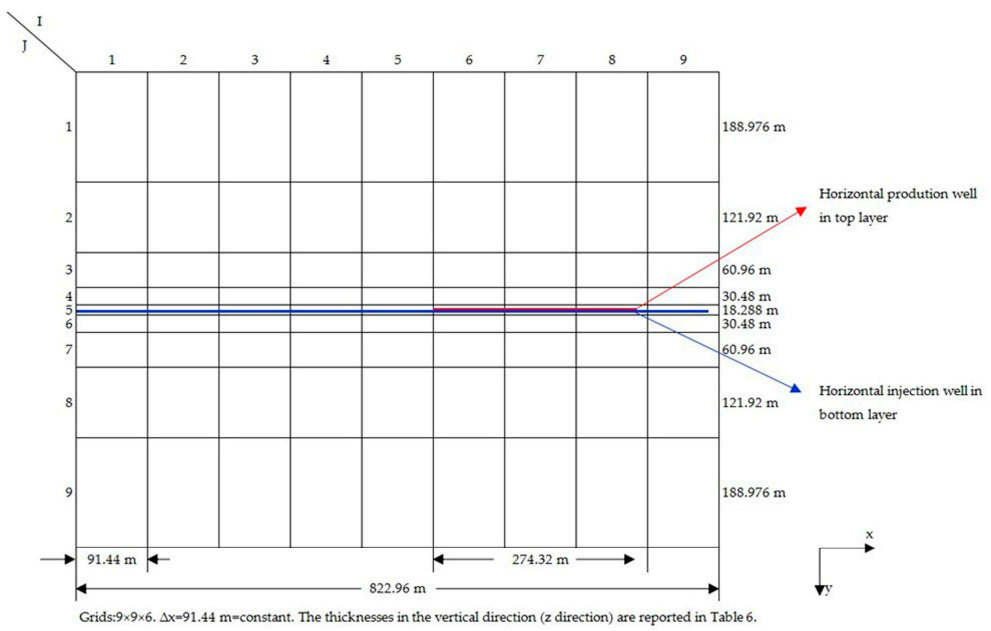

Figure 12. Grids system and well location of the case. 
(a)

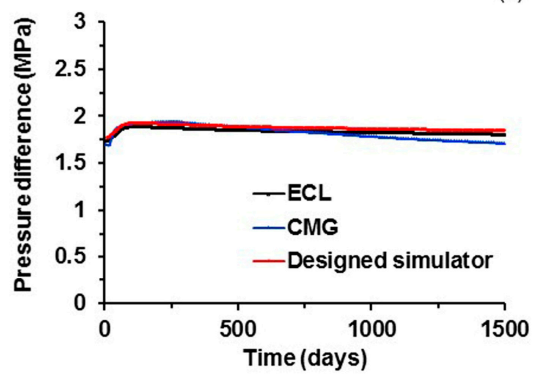

(c)

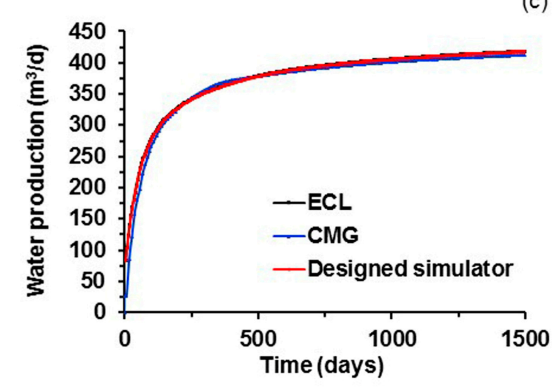

(e)

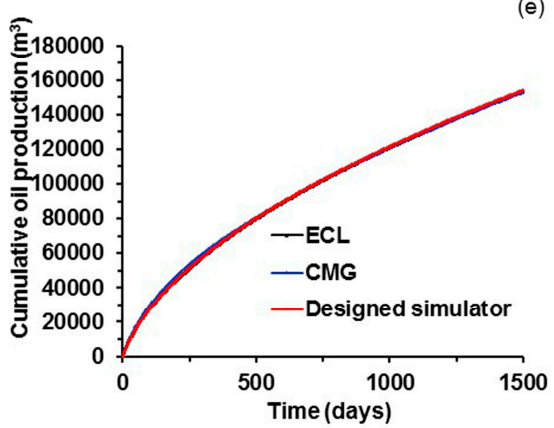

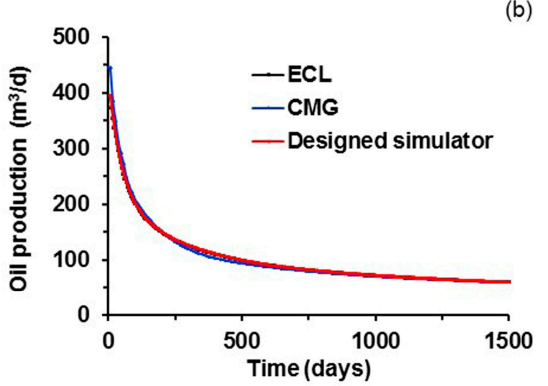

(d)

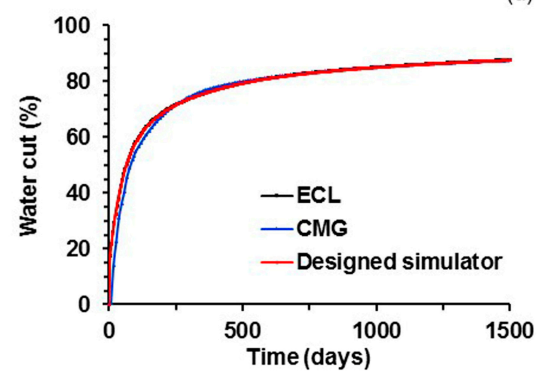

(f)

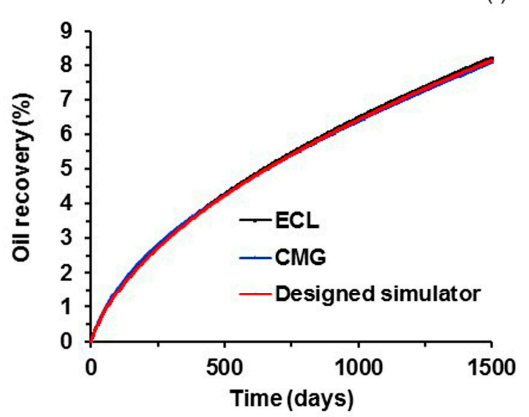

Figure 13. Comparison result of (a) pressure difference; (b) oil production; (c) water production; (d) water cut; (e) cumulative oil production; and (f) oil recovery of ECLIPSE V2013.1, CMG V2012 software and designed simulator in running the case.

However, there is no widely accepted commercial software that considers non-Newtonian flow. Therefore, we compared its simulation results to the data of an actual Bohai Bay oilfield heavy oil displacement experiment for validation.

The main parameters of the displacement experiment and the main input parameters of the designed simulator are provided in Tables 9 and 10 and Figure 14. It is important to note that the viscosity and TPG were calculated by the above corresponding Arrhenius equation in addition to the fitting formula of the mobility and the TPG, respectively. The comparison result of the pressure difference, oil production, water production, water cut, cumulative oil production and oil recovery are indicated in Figure 15. This figure reveals the simulation result was close to the experimental result. There was a difference of only $0.78 \%$ in oil recovery when $10 \mathrm{PV}$ water was injected. Moreover, the actual oil saturation distribution was obtained by the saturation detector when 10 PV water was injected in the experiment (Figure 16a). Figure 16b presents the oil saturation distribution by the designed simulator. A comparison of the two oil saturation distributions indicates that there were some differences between them. This was attributed to the accuracy of the saturation detector, which was limited by laboratory conditions and influenced by the position and number of probes, experimental operation and other factors. Nevertheless, from the overall oil saturation distribution 
and the trend of the oil saturation change, they were considered similar. Overall, the validation with non-Newtonian flow was positive and acceptable.

Table 9. Main Parameters of heavy oil displacement experiment and numerical simulation.

\begin{tabular}{|c|c|c|c|}
\hline $\begin{array}{c}\text { Parameters of the Heavy Oil } \\
\text { Displacement Experiment }\end{array}$ & Value & Input Parameters of the Designed Simulator & Value \\
\hline Temperature, ${ }^{\circ} \mathrm{C}$ & 65 & Number of blocks along $x$ & 59 \\
\hline Oil sample number & $\# 1$ & Number of blocks along $y$ & 5 \\
\hline Core dimensions, $\mathrm{cm}$ & $29.5 \times 4.5 \times 4.5$ & Number of blocks along $z$ & 5 \\
\hline Porosity, fraction & 0.246 & Length of the block along $x, \mathrm{~cm}$ & 0.5 \\
\hline Permeability, $\mathrm{mD}$ & 1200 & Length of the block along $y, \mathrm{~cm}$ & 0.9 \\
\hline Rock compressibility, $\mathrm{MPa}^{-1}$ & $2.6 \times 10^{-4}$ & Length of the block along $z, \mathrm{~cm}$ & 0.9 \\
\hline Stock tank oil density, $\mathrm{g} / \mathrm{cm}^{3}$ & 0.956 & Initial porosity, fraction & 0.246 \\
\hline Oil viscosity, $\mathrm{mPa} \cdot \mathrm{s}$ & 180 & Initial permeability in $x$ direction, $\mathrm{mD}$ & 1200 \\
\hline Oil compressibility, $\mathrm{MPa}^{-1}$ & $1.0 \times 10^{-3}$ & Initial permeability in $y$ direction, $\mathrm{mD}$ & 1200 \\
\hline Oil formation volume factor & 1.066 & Initial permeability in $z$ direction, $\mathrm{mD}$ & 120 \\
\hline Water density, $\mathrm{g} / \mathrm{cm}^{3}$ & 1 & Rock compressibility, $\mathrm{MPa}^{-1}$ & $2.6 \times 10^{-4}$ \\
\hline Water viscosity, $\mathrm{mPa} \cdot \mathrm{s}$ & 0.52 & Stock tank oil density, $\mathrm{g} / \mathrm{cm}^{3}$ & 0.956 \\
\hline Water compressibility, $\mathrm{MPa}^{-1}$ & $4.6 \times 10^{-4}$ & Initial oil viscosity, $\mathrm{mPa} \cdot \mathrm{s}$ & 180 \\
\hline Water formation volume factor & 1.012 & Oil compressibility, $\mathrm{MPa}^{-1}$ & $1.0 \times 10^{-3}$ \\
\hline Initial pressure, $\mathrm{MPa}$ & 2 & Oil formation volume factor & 1.066 \\
\hline Water saturation, fraction & 0.272 & Initial water density, $\mathrm{g} / \mathrm{cm}^{3}$ & 1 \\
\hline Oil saturation, fraction & 0.728 & Water viscosity, $\mathrm{mPa} \cdot \mathrm{s}$ & 0.52 \\
\hline $\begin{array}{l}\text { Bottom hole pressure of } \\
\text { production well, } \mathrm{MPa}\end{array}$ & 2 & Water compressibility, $\mathrm{MPa}^{-1}$ & $4.6 \times 10^{-4}$ \\
\hline $\begin{array}{l}\text { Water rate of injection well, } \\
\qquad \mathrm{cm}^{3} / \mathrm{min}\end{array}$ & 0.5 & Water formation volume factor & 1.012 \\
\hline \multirow{6}{*}{$\mathrm{TPG}, \mathrm{MPa} / \mathrm{m}$} & 0.0005 & Initial pressure, $\mathrm{MPa}$ & 2 \\
\hline & & initial water saturation, fraction & 0.272 \\
\hline & & initial oil saturation, fraction & 0.728 \\
\hline & & Bottom hole pressure of production well, $\mathrm{MPa}$ & 2 \\
\hline & & Water rate of injection well, $\mathrm{cm}^{3} \mathrm{~min}^{-1}$ & 0.5 \\
\hline & & $\mathrm{TPG}, \mathrm{MPa} / \mathrm{m}$ & 0.0005 \\
\hline
\end{tabular}

Table 10. Relative permeabilities and capillary pressures used in the simulation running the heavy oil displacement experiment.

\begin{tabular}{cccc}
\hline $\boldsymbol{S}_{\boldsymbol{w}}$ & $\boldsymbol{k}_{\boldsymbol{r w}}$ & $\boldsymbol{k}_{\boldsymbol{r} \boldsymbol{o}}$ & $\boldsymbol{P}_{\text {cow }}, \boldsymbol{M P a}$ \\
\hline 0.2720 & 0.0000 & 1.0000 & 0.1674 \\
0.3014 & 0.0024 & 0.8531 & 0.1473 \\
0.3308 & 0.0039 & 0.7156 & 0.1268 \\
0.3602 & 0.0051 & 0.5877 & 0.1088 \\
0.3896 & 0.0071 & 0.4692 & 0.0962 \\
0.4190 & 0.0098 & 0.3578 & 0.0830 \\
0.4484 & 0.0142 & 0.2583 & 0.0727 \\
0.4778 & 0.0257 & 0.1659 & 0.0629 \\
0.5072 & 0.0488 & 0.0723 & 0.0549 \\
0.5366 & 0.0829 & 0.0213 & 0.0477 \\
0.5660 & 0.1209 & 0.0118 & 0.0420 \\
0.5954 & 0.1588 & 0.0088 & 0.0362 \\
0.6248 & 0.1943 & 0.0071 & 0.0307 \\
0.6542 & 0.2299 & 0.0061 & 0.0261 \\
0.6836 & 0.2654 & 0.0052 & 0.0186 \\
0.7130 & 0.3033 & 0.0038 & 0.0113 \\
0.7424 & 0.3452 & 0.0012 & 0.0043 \\
0.7718 & 0.3886 & 0.0000 & 0.0000 \\
\hline
\end{tabular}



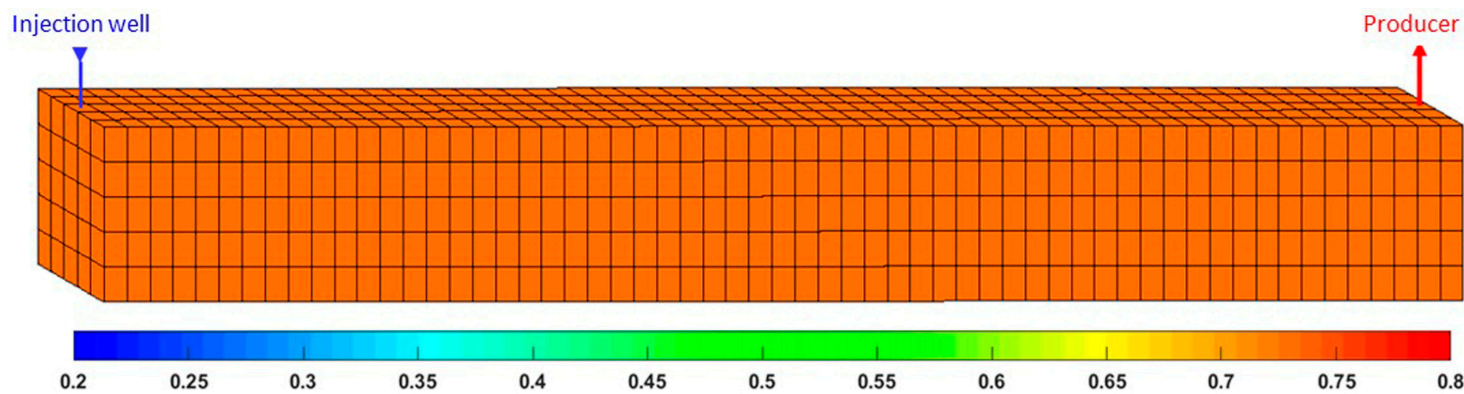

Figure 14. Well location and 3D distributions of heavy oil saturation in the initial state.

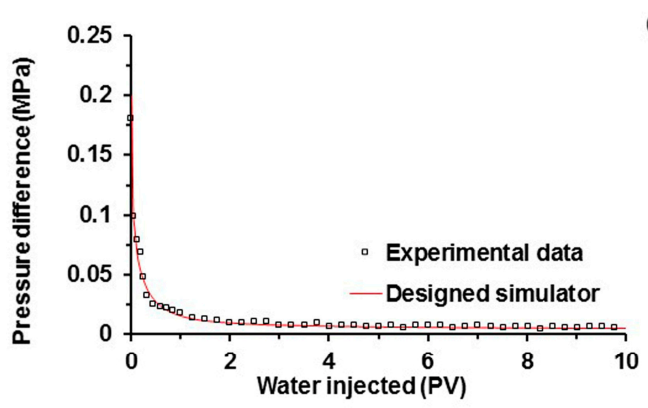

(a)

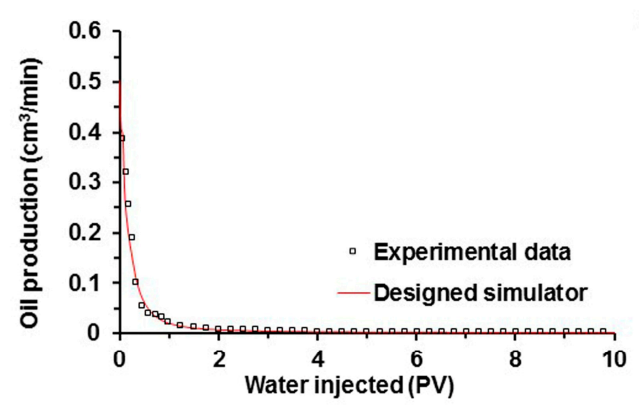

(b)

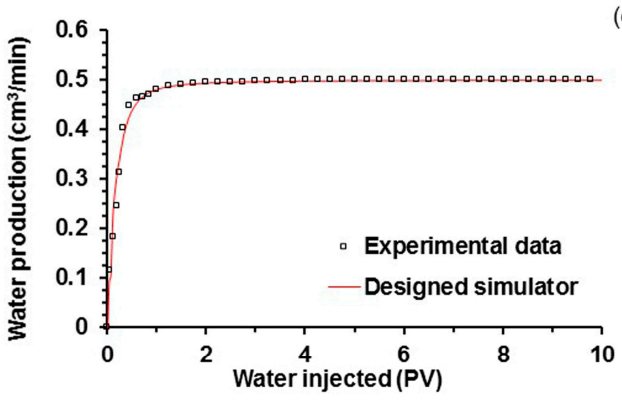

(c)

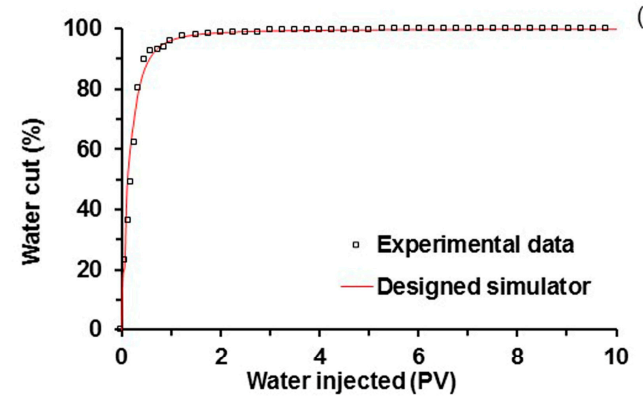

(d)

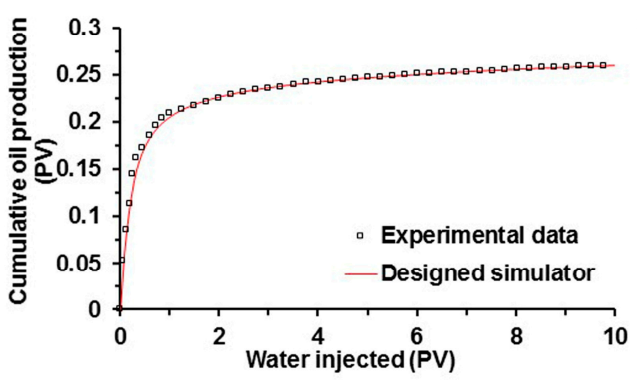

(e)

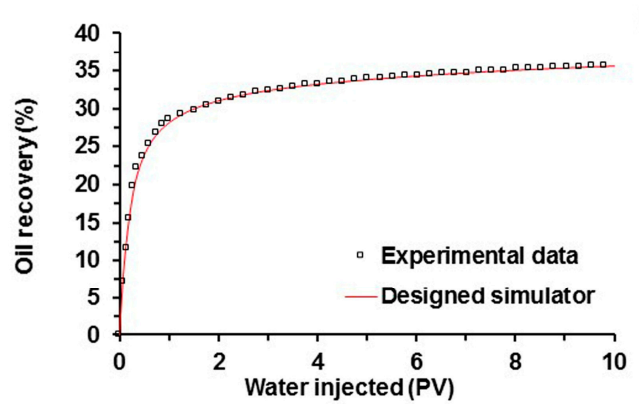

Figure 15. Comparison result of (a) pressure difference; (b) oil production; (c) water production; (d) water cut; (e) cumulative oil production; and (f) oil recovery of the heavy oil displacement experiment and designed simulator in simulating the displacement experiment. 


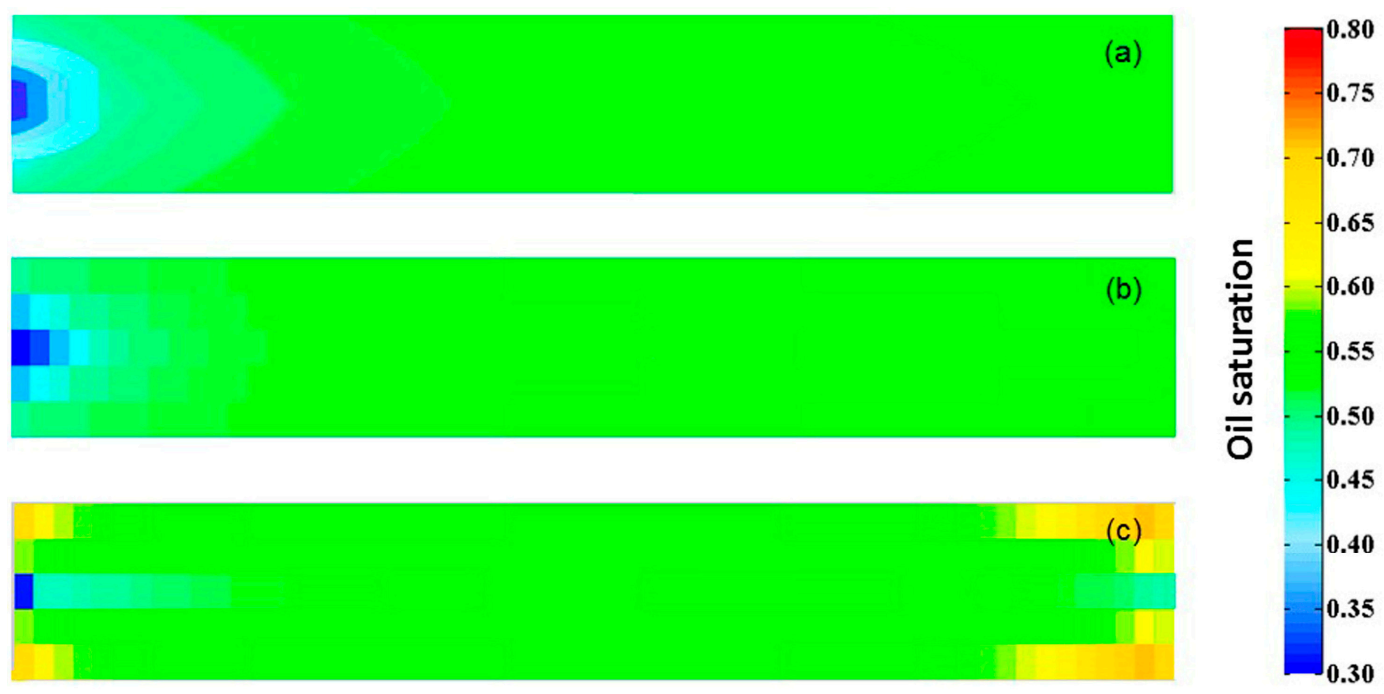

Figure 16. Oil saturation distribution when $10 \mathrm{PV}$ water was injected: (a) by saturation detector, $\lambda=0.0005 \mathrm{MPa} / \mathrm{m}$; (b) by designed simulator, $\lambda=0.0005 \mathrm{MPa} / \mathrm{m}$; and (c) by the designed simulator, $\lambda=0.0750 \mathrm{MPa} / \mathrm{m}$.

Meanwhile, the effect of grid size on the simulation result of the designed simulator under fingering was investigated by simulating a same case with different grid sizes, whose model and other parameters were same to those used in simulating the heavy oil displacement experiment. The grid information is provided in Table 11 and the comparison results are presented in Figure 17. It can be seen from Figure 17 that the effect of grid size on the simulation under fingering and the numerical dispersion were acceptable.

Table 11. The grid information of the simulations used to study the impact of grid size.

\begin{tabular}{cccccc}
\hline \multirow{2}{*}{ Parameters } & \multicolumn{5}{c}{ Simulation Number } \\
\cline { 2 - 6 } & $\mathbf{\# 1}$ & $\mathbf{\# 2}$ & $\mathbf{\# 3}$ & $\mathbf{\# 4}$ & $\# \mathbf{5}$ \\
\hline Number of blocks along $x$ & 15 & 31 & 59 & 71 & 81 \\
Number of blocks along $y$ & 3 & 3 & 5 & 7 & 9 \\
Number of blocks along $z$ & 3 & 3 & 5 & 7 & 9 \\
Length of the block along $x, \mathrm{~cm}$ & 1.9667 & 0.9516 & 0.5 & 0.4155 & 0.3642 \\
Length of the block along $y, \mathrm{~cm}$ & 1.5 & 1.5 & 0.9 & 0.6429 & 0.5 \\
Length of the block along $z, \mathrm{~cm}$ & 1.5 & 1.5 & 0.9 & 0.6429 & 0.5 \\
\hline
\end{tabular}




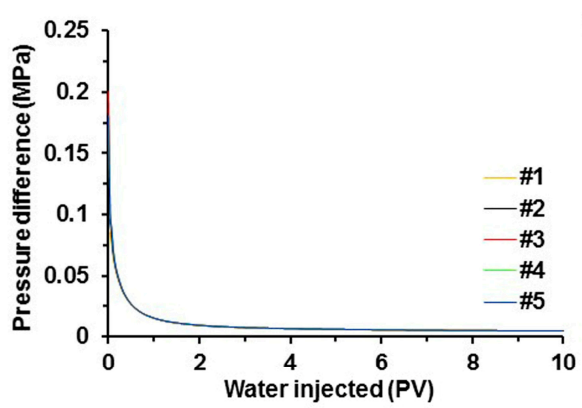

(a)

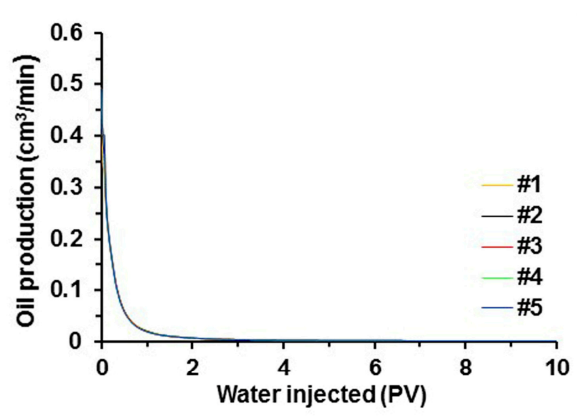

(b)
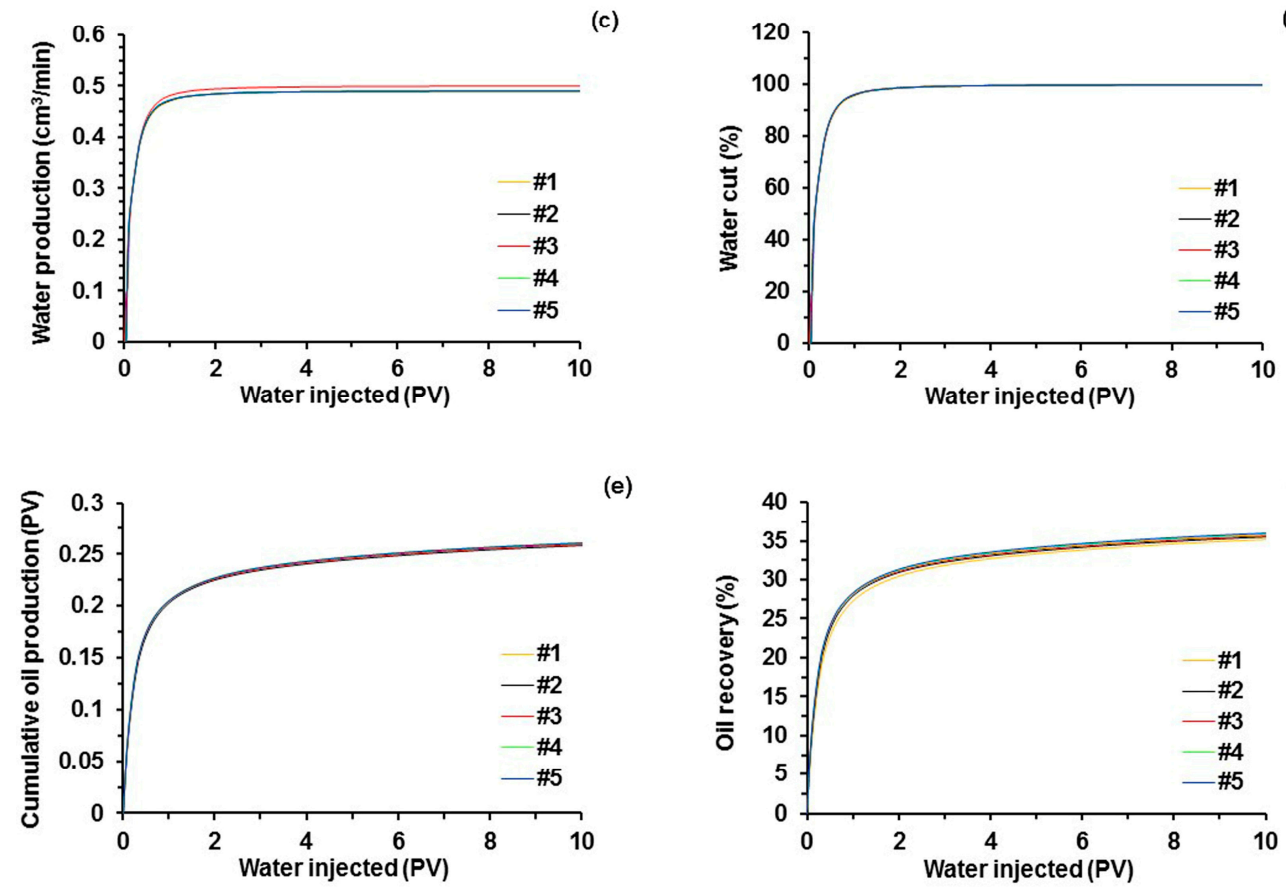

(e)

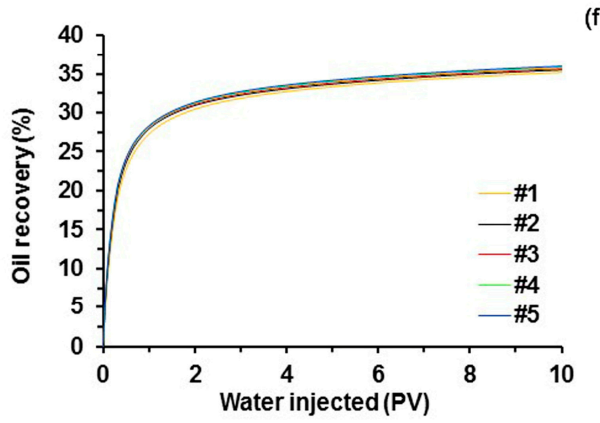

Figure 17. Comparison result of (a) pressure difference; (b) oil production; (c) water production; (d) water cut; (e) cumulative oil production; and (f) oil recovery of the designed simulator in running a same case with different grid sizes, whose model and other parameters were same to those used in simulating the heavy oil displacement experiment.

\subsubsection{TPG Sensitivity}

Three more simulations were undertaken to analyze the TPG sensitivity. They considered the TPG of $0.0250 \mathrm{MPa} / \mathrm{m}, 0.0500 \mathrm{MPa} / \mathrm{m}$, and $0.0750 \mathrm{MPa} / \mathrm{m}$. The rest of the experimental conditions and the simulation parameters were the same. Figure 18 provides the oil recovery at different TPGs. This figure demonstrates that the oil recovery decreased with an increase in the TPG, and the point where the recovery growth of heavy oil with a higher TPG slows down is earlier than that of heavy oil with a smaller TPG. The oil recovery was close to each other when the volume of injected water was lower than $0.2 \mathrm{PV}$ and decreased with an increase in the TPG after 0.2 PV water was injected. After 1.2 PV water was injected, the recovery growth of the heavy oil with $\lambda=0.0750 \mathrm{MPa} / \mathrm{m}$ became smooth, but that of the heavy oil with $\lambda=0.0005 \mathrm{MPa} / \mathrm{m}$ continued to increase until the amount of injected water attained 3.0 PV, and the oil recovery growth slowed down. When the volume of injected water reached $10 \mathrm{PV}$, the oil recovery of the heavy oil with $\lambda=0.0750 \mathrm{MPa} / \mathrm{m}$ was $11.55 \%$ less than that of the heavy oil with $\lambda=0.0005 \mathrm{MPa} / \mathrm{m}$. The plot of oil saturation for the heavy oil with $\lambda=0.0750$ $\mathrm{MPa} / \mathrm{m}$ when $10 \mathrm{PV}$ water was injected is presented in Figure 16c. The remaining oil saturation of the heavy oil with $\lambda=0.0750 \mathrm{MPa} / \mathrm{m}$ was more than that of the heavy oil with $\lambda=0.0005 \mathrm{MPa} / \mathrm{m}$ as 
seen in the comparison between Figures 16c and 16b. The remaining heavy oil increased as the TPG increased because the flow of heavy oil in the porous medium became more challenging when the TPG was higher.

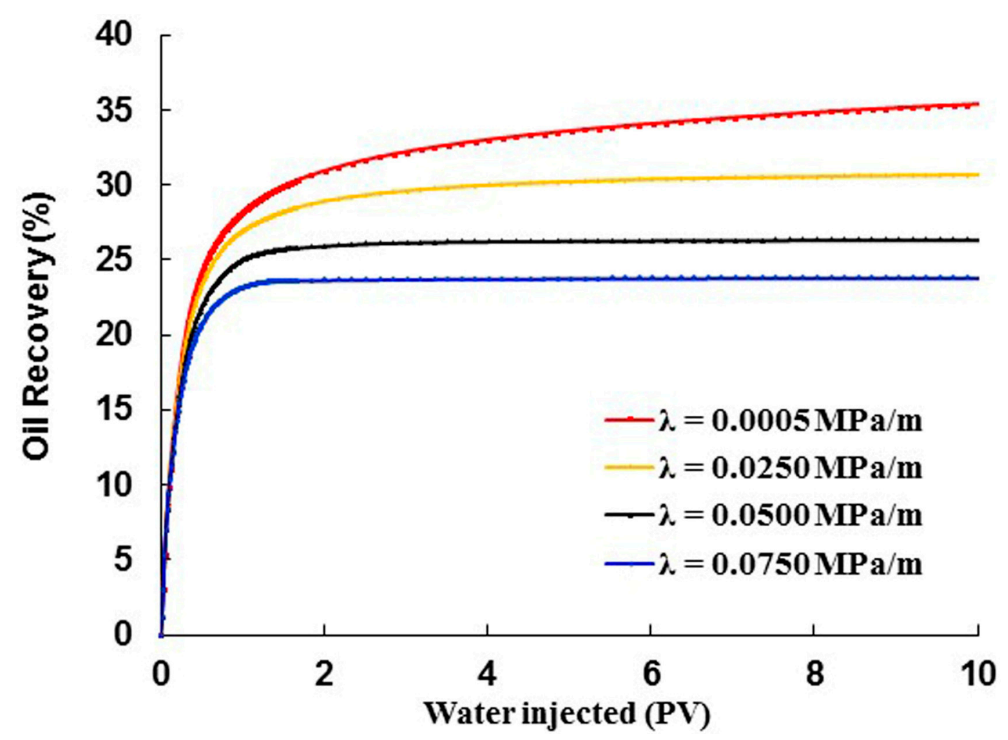

Figure 18. Oil recovery at different TPGs by the designed simulator.

\section{Conclusions}

The primary objective of this study was to investigate the flow characteristics of heavy oil in Bohai Bay oilfield in order to provide theoretical and technical guides for the development of heavy oil fields. Experimental results indicated that heavy oil in Bohai Bay oilfield was a Bingham liquid, and its rheological properties were related to temperature and asphaltene content. The yield stress and viscosity decreased with an increase in temperature, and the viscosity-temperature curve was in accordance with the Arrhenius equation. In terms of asphaltene content, the viscosity increased as the asphaltene content increased. The heavy oil did not flow until the pressure gradient exceeded the TPG, while the TPG increased with the rise in viscosity and with a decrease in permeability. Moreover, the TPG had a power-law relationship with mobility, and it decreased as the mobility increased. The TPG existed under a specific condition, and the critical viscosity for the existence of TPG in Bohai Bay oilfield had a range of $42-54 \mathrm{mPa} \cdot \mathrm{s}$. It is recommended to reduce the viscosity below the critical viscosity. Furthermore, the relationship between a flow rate and a pressure gradient was primarily a straight line, but it did not pass through the origin of the coordinate axes. The flow of heavy oil did not follow Darcy's law, but instead followed non-Newtonian flow. A 3D two-phase heavy oil simulator that considered the non-Newtonian flow characteristics of heavy oil was designed and validated with high reliability when compared to the simulation results run in ECLIPSE V2013.1 and CMG V2012 software as well as the results obtained during physical experiments. A TPG sensitivity analysis by the simulator indicated that the TPG significantly influenced the oil recovery. Compared with the case of $\lambda=0.0005 \mathrm{MPa} / \mathrm{m}$, the heavy oil with $\lambda=0.0750 \mathrm{MPa} / \mathrm{m}$ had a lower oil recovery by a difference of $11.55 \%$. There was more remaining heavy oil in the porous medium when the TPG was higher. To minimize the impact of the TPG on the production of a heavy oil field, thermal recovery methods are recommended to reduce the viscosity of heavy oil and to increase the mobility of heavy oil $[67,68]$, which should be followed by a reduction in the TPG to improve heavy oil recovery.

Acknowledgments: This work was supported by National Science and Technology Major Project of China (No. 2016ZX05025-001-005 and No. 2016ZX05025-003-010) and the China Scholarship Council (201606440044). 
Author Contributions: Weiying Wang and Yiqiang Li conceived and designed the experiments; Wenli Ke and Debin Kong performed the experiments; Xiankang Xin, Gaoming Yu, Zhongzhi Zhang, Maolin Zhang, Keliu Wu and Zhangxin Chen analyzed the data; Weiying Wang and Yiqiang Li contributed reagents/materials/analysis tools; Xiankang Xin wrote the paper.

Conflicts of Interest: The authors declare no conflict of interest.

\section{References}

1. Daily Demand for Crude Oil Worldwide from 2006 to 2016. Available online: https:/ / www.statista.com/ statistics/271823/daily-global-crude-oil-demand-since-2006/ (accessed on 25 October 2017).

2. Lu, T.; Li, Z.; Zhou, Y. Flow Behavior and Displacement Mechanisms of Nanoparticle Stabilized Foam Flooding for Enhanced Heavy Oil Recovery. Energies 2017, 10, 560. [CrossRef]

3. Huc, A.Y. Heavy Crude Oils: From Geology to Upgrading: An Overview; Editions Technip: Paris, France, 2011; p. 11. ISBN 978-2-7108-0890-9.

4. Mai, A.; Bryan, J.; Goodarzi, N.; Kantas, A. Insights into Non-Thermal Recovery of Heavy Oil. J. Can. Pet. Technol. 2009, 48, 27. [CrossRef]

5. Enrique, S.C.; Patsy, V.R.G.; Ulises, M.C.; Sergio, E.Q.C. Effect of the Temperature on the Non-Newtonian Behavior of Heavy Oils. Energy Fuels 2015, 29, 2883-2889.

6. Ghannam, M.T.; Hasan, S.W.; Abu-Jdayil, B.; Esmail, N. Rheological Properties of Heavy \& Light Crude Oil Mixtures for Improving Flowability. J. Pet. Sci. Eng. 2012, 81, 122-128.

7. Luo, P.; Gu, Y. Effects of Asphaltene Content on the Heavy Oil Viscosity at Different Temperatures. Fuel 2007, 86, 1069-1078. [CrossRef]

8. Ghanavati, M.; Shojaei, M.J.; Ramazani, R.S.A. Effects of Asphaltene Content and Temperature on Viscosity of Iranian Heavy Crude Oil: Experimental and Modeling Study. Energy Fuels 2013, 27, 7217-7232. [CrossRef]

9. Wang, S.; Huang, Y.; Civan, F. Experimental and Theoretical Investigation of the Zaoyuan Field Heavy Oil Flow through Porous Media. J. Pet. Sci. Eng. 2006, 50, 83-101. [CrossRef]

10. Bird, R.B.; Stewart, W.E.; Lightfoot, E.N. Transport Phenomena, 2nd ed.; John Wiley \& Sons Inc.: New York, NY, USA, 2002; pp. 21-36. ISBN 0471410772.

11. Macosko, C.W. Rheology: Principles, Measurements, and Applications; Wiley-VCH: Weinheim, Germany, 1994; pp. 92-101. ISBN 1560815795.

12. Bassane, J.F.P.; Sad, C.M.S.; Neto, D.M.C.; Santos, M.F.P.; Santos, F.D. Study of the Effect of Temperature and Gas Condensate Addition on the Viscosity of Heavy Oils. J. Pet. Sci. Eng. 2016, 142, 163-169. [CrossRef]

13. Mullins, O.C.; Sheu, E.Y. Structures and Dynamics of Asphaltenes; Plenum Press: New York, NY, USA, 1998; p. 15. ISBN 1560815795.

14. Henaut, I.; Argillier, J.F.; Pierre, C.; Moan, M. Thermal Flow Properties of Heavy Oils. In Proceedings of the Offshore Technology Conference, Houston, TX, USA, 5-8 May 2003.

15. Ovalles, C.; Rogel, E.; Segerstrom, J. Improvement of Flow Properties of Heavy Oils Using Asphaltene Modifiers. In Proceedings of the SPE Annual Technical conference and Exhibition, Denver, CO, USA, 30 October-2 November 2011.

16. Yen, T.F.; Chilingarian, G.V. Asphaltenes and Asphalts, 1st ed.; Elsevier Science: Amsterdam, The Netherlands, 1994; pp. 249-295. ISBN 044488291X.

17. Argillier, J.F.; Coustet, C.; Henaut, I. Heavy Oil Rheology as a Function of Asphaltene and Resin Content and Temperature. In Proceedings of the SPE International Thermal Operations and Heavy Oil Symposium and International Horizontal Well Technology Conference, Calgary, AB, Canada, 4-7 November 2002.

18. Malkin, A.Y.; Khadzhiev, S.N. On the Rheology of Oil (Review). Pet. Chem. 2016, 56, 541-551. [CrossRef]

19. Liu, H.; Wang, J.; Xie, Y.; Ma, D.; Shi, X. Flow Characteristics of Heavy Oil through Porous Media. Energy Sources Part A 2012, 34, 347-359. [CrossRef]

20. Chen, M.; Rossen, W.; Yortsos, Y.C. The Flow and Displacement in Porous Media of Fluids with Yield Stress. Chem. Eng. Sci. 2005, 60, 4183-4202. [CrossRef]

21. Evdokimov, I.N.; Eliseev, N.Y.; Eliseev, D.Y. Rheological Evidence of Structural Phase Transitions in Asphaltene-Containing Petroleum Fluids. J. Pet. Sci. Eng. 2001, 30, 199-211. [CrossRef]

22. Luo, Y.; Cheng, L.; Ding, Z. A Transient Flow Model of Non-Newtonian Heavy Oil under Different Bottom-hole Producing Pressure Conditions. Pet. Sci. Technol. 2014, 32, 505-512. [CrossRef] 
23. Dong, X.; Liu, H.; Wang, Q.; Pang, Z.; Wang, C. Non-Newtonian Flow Characterization of Heavy Crude Oil in Porous Media. J. Pet. Explor. Prod. Technol. 2013, 3, 43-53. [CrossRef]

24. Laaber, P. Numerical Simulation of a Three-Dimensional Bingham Fluid Flow. Master's Thesis, Johannes Kepler University Linz, Linz, Austria, March 2008.

25. Boveta, E.; Chiaiaa, B.; Preziosib, L. A New Model for Snow Avalanche Dynamics Based on Bingham Fluids. Meccanica 2010, 45, 753-765. [CrossRef]

26. Mirzajanzade, A.K.H.; Akhmedov, Z.M.; Gurbanov, R.S.; Amirov, A.D.; Barenblatt, G.I.; Entov, V.M.; Zaitsev, Y.V. On the Special features of Oil and Gas Field Development due to Effects of Initial Pressure Gradient. In Proceedings of the 8th World Petroleum Congress, Moscow, USSR, 13-18 June 1971.

27. Zeng, B.; Cheng, L.; Hao, F. Experiment and Mechanism Analysis on Threshold Pressure Gradient with Different Fluids. In Proceedings of the 34th Annual SPE International Conference and Exhibition, Tinapa-Calabar, Nigeria, 31 July-7 August 2010.

28. Ning, L. Experimental Method and Its Applications of Threshold Pressure Gradient of Heavy Oil in Porous Media. J. Pet. Univ. 2011, 24, 59-62.

29. Lu, C.; Wang, J.; Sun, Z. An Experiment Study on Starting Pressure Gradient of Fluids Flow in Low Permeability Sandstone Porous Media. Pet. Explor. Dev. 2002, 29, 86-87.

30. Wang, W.; Yu, G.; Ke, W.; Wang, Y.; Ge, Y. Experimental Study of Nonlinear Seepage for Heavy Oil. Pet. Geol. Exp. 2013, 35, 464-467.

31. Pang, Z.; Liu, H. The Transient Method and Experimental Study on Threshold Pressure Gradient of Heavy Oil in Porous Media. Open Pet. Eng. J. 2012, 5, 7-13. [CrossRef]

32. Sun, J. Threshold pressure gradient study on non-Newtonian flow of heavy oil reservoirs in Shengli oilfield. Pet. Geol. Recover. Effic. 2010, 17, 74-77.

33. Zarivnyy, O. Investigation of the Two-and Three-Phase Relative Permeability Relation in Carbon Dioxide-Oil-Water Systems for Light and Heavy Oil Reservoirs. Master's Thesis, University of Regina, Regina, SK, Canada, August 2011.

34. Alizadeh, A.H.; Piri, M. Three-phase flow in porous media: A review of experimental studies on relative permeability. Rev. Geophys. 2014, 52, 468-521. [CrossRef]

35. Yang, Q. Study on Relative Permeabilities in Condition of Two-Phase Flooding. Ph.D. Thesis, China University of Geosciences, Beijing, China, April 2012.

36. Honarpour, M.; Mahmood, S.M. Relative-permeability measurements: An overview. J. Pet. Technol. 1988, 40, 963-966. [CrossRef]

37. Zhang, D.; Peng, J.; Gu, Y.; Leng, Y. Experimental Study on Threshold Pressure Gradient of Heavy Oil Reservoir. Xinjiang Pet. Geol. 2012, 33, 201-204.

38. Wang, Z.; Zhang, D.; Yang, J.; Kou, G.; Yang, F. Experimental Study on Percolation Characteristics of Ordinary Heavy Oil Reservoirs: A Case Study from the Qigu Formation Reservoir in Nine-4 Block of Xinjiang Oilfield. Oil Gas Geol. 2012, 33, 302-306.

39. Maini, B.; Coskuner, G.; Jha, K. A Comparison of Steady-State and Unsteady-State Relative Permeabilities of Viscocities Oil and Water in Ottawa Sand. J. Can. Pet. Technol. 1990, 29, 72-77. [CrossRef]

40. Bian, X.; Zhou, L.; Zhang, J.; Zhang, S. Effect of Non-Darcy Flow on the Integral Fracturing Design of Low-Permeability Petroleum Reservoirs. Energy Technol. 2016, 4, 263-270. [CrossRef]

41. Wang, J.; Dong, M.; Asghari, K. Effect of Oil Viscosity on Heavy Oil-Water Relative Permeability Curves. In Proceedings of the SPE/DOE Symposium on Improved Oil Recovery, Tulsa, OK, USA, 22-26 April 2006.

42. Torabi, F.; Mosavat, N.; Zarivnyy, O. Predicting heavy oil/water relative permeability using modified Corey-based correlations. Fuel 2016, 163, 196-204. [CrossRef]

43. Mai, A. Mechanisms of Heavy Oil Recovery by Waterflooding. Ph.D. Thesis, University of Calgary, Calgary, AB, Canada, April 2008.

44. Doorwar, S.; Mohanty, K.K. Viscous-Fingering Function for Unstable Immiscible Flows. SPE J. 2017, 22, 19-31. [CrossRef]

45. Saramito, P.; Wachs, A. Progress in numerical simulation of yield stress fluid flows. Rheol. Acta 2017, 56, 211-230. [CrossRef]

46. Chen, S.; Zhang, C.; Feng, Y.; Sun, Q.; Jin, F. Three-dimensional simulations of Bingham plastic flows with the multiple-relaxation-time lattice Boltzmann model. Eng. Appl. Comput. Fluid Mech. 2016, 10, 346-358. [CrossRef] 
47. Sochi, T. Modelling the Flow of Yield-Stress Fluids in Porous Media. Transp. Porous Media 2010, 85, 489-503. [CrossRef]

48. Balhoff, M.T.; Thompson, K.E. Modeling the Steady Flow of Yield-stress Fluids in Packed Beds. AIChE J. 2004, 50, 3034-3048. [CrossRef]

49. Wu, Y.S.; Pruess, K.A. Numerical Method for Simulating non-Newtonian Fluid Flow and Displacement in Porous Media. Adv. Water Resour. 1998, 21, 351-362. [CrossRef]

50. Chen, Z.; Huan, G.; Li, B. An Improved IMPES Method for Two-Phase Flow in Porous Media. Transp. Porous Media 2004, 54, 361-376. [CrossRef]

51. Ahmadpour, M.; Siavashi, M.; Doranehgard, M.H. Numerical Simulation of Two-phase Flow in Fractured Porous Media Using Streamline Simulation and IMPES Methods and Comparing Results with a Commercial Software. J. Cent. South Univ. 2016, 23, 2630-2637. [CrossRef]

52. Chen, Z. Reservoir Simulation: Mathematical Techniques in Oil Recovery; Society for Industrial and Applied Mathematics: Philadelphia, PA, USA, 2007; pp. 94-101. ISBN 978-0-898716-40-5.

53. Jo, G.; Kwak, D.Y. An IMPES Scheme for a Two-phase Flow in Heterogeneous Porous Media Using a Structured Grid. Comput. Methods Appl. Mech. Eng. 2017, 317, 684-701. [CrossRef]

54. Salama, A.; Sun, S.; El-Amin, M. An Efficient Implicit-pressure/Explicit-saturation-method-based Shifting-matrix Algorithm to Simulate Two-phase, Immiscible Flow in Porous Media with Application to $\mathrm{CO}_{2}$ Sequestration in the Subsurface. SPE J. 2013, 18, 1092-1100. [CrossRef]

55. Sheldon, J.W.; Cardwell, J.W.T. One-dimensional, Incompressible, Noncapillary, Two-phase Fluid Flow in a Porous Medium. Pet. Trans. AIME 1959, 216, 290-296.

56. Stone, H.L.; Garder, J.A.O. Analysis of Gas-cap or Dissolved-gas Drive Reservoirs. Soc. Pet. Eng. J. 1961, 1, 92-104. [CrossRef]

57. Wu, Y.S. Multiphase Fluid Flow in Porous and Fractured Reservoirs; Gulf Professional Publishing: Houston, TX, USA, 2015; pp. 127-166. ISBN 978-0-12-803848-2.

58. Zienkiewicz, O.C.; Taylor, R.L.; Nithiarasu, P. The Finite Element Method for Fluid Dynamics, 7th ed.; Elsevier Publishing: Atlanta, GA, USA, 2014; pp. 163-194. ISBN 978-1-85617-635-4.

59. Riber, S.; Valette, R.; Mesri, Y.; Hachem, E. Adaptive variational multiscale method for bingham flows. Comput. Fluids 2016, 138, 51-60. [CrossRef]

60. Chen, Z.; Huan, G.; Ma, Y. Computational Methods for Multiphase Flows in Porous Media; Society for Industrial and Applied Mathematics: Philadelphia, PA, USA, 2006; pp. 259-270. ISBN 978-0-89871-606-1.

61. Viswanath, D.S.; Dutt, N.V.K.; Ghosh, T.K.; Prasad, D.H.L.; Rani, K.Y. Viscosity of Liquids: Theory, Estimation, Experiment, and Data; Springer: Dordrecht, The Netherlands, 2007; pp. 138-139. ISBN 978-1-4020-5481-5.

62. Han, C.D. Rheology and Processing of Polymeric Materials; Oxford University Press: New York, NY, USA, 2007; pp. 206-207. ISBN 978-0-19-518782-3.

63. Wu, Q.; Wu, J. Polymer Rheology; Higher Education Press: Beijing, China, 2002; pp. 44-47. ISBN 7-04-011582-4.

64. Jia, H.; Liu, P.; Pu, W.; Ma, X.; Zhang, J.; Gan, L. In Situ Catalytic Upgrading of Heavy Crude Oil through Low-Temperature Oxidation. Pet. Sci. 2016, 13, 476-488. [CrossRef]

65. Ke, W. Research on Nonlinear Percolation Law of Heavy Oil. Master's Thesis, Yangtze University, Wuhan, China, May 2013.

66. Nghiem, L.; Collins, D.A.; Sharma, R. Seventh SPE Comparative Solution Project: Modelling of Horizontal Wells in Reservoir Simulation. In Proceedings of the 11th SPE Symposium on Reservoir Simulation, Anaheim, CA, USA, 17-20 February 1991.

67. Alvarado, V.; Manrique, E. Enhanced Oil Recovery: An Update Review. Energies 2010, 3, $1529-1575$. [CrossRef]

68. Xu, W.; Zhao, J.; Chen, Z.; Shan, J.; Sun, Y. Experimental and Simulation Studies on Steam Stimulation with Multiple Fluids for Offshore Heavy Oil Reservoirs. Int. J. Numer. Anal. Model.-B 2014, 5, 31-45.

(C) 2017 by the authors. Licensee MDPI, Basel, Switzerland. This article is an open access article distributed under the terms and conditions of the Creative Commons Attribution (CC BY) license (http:/ / creativecommons.org/licenses/by/4.0/). 